\title{
Insights into the Complex Photophysics and Photochemistry of the Simplest Nitroaromatic Compound: A CASPT2//CASSCF Study on Nitrobenzene
}

\author{
Angelo Giussani ${ }^{*}, \dagger+{ }^{\dagger}$ and Graham A. Worth ${ }^{\dagger, \ddagger}$ \\ ${ }^{\dagger}$ School of Chemistry, University of Birmingham, Edgbaston B15 2TT, U.K. \\ ${ }^{*}$ Department of Chemistry, University College London, 20 Gordon Street, London WC1H 0AJ, U.K.
}

Supporting Information

ABSTRACT: Nitrobenzene is the simplest nitroaromatic compound and yet is characterized by a challenging and rich photophysics and photochemistry. In the present contribution, the main decay paths undertaken by the system after UV absorption from both the brightest ${ }^{1}\left(\mathrm{~L}_{\mathrm{a}} \pi \pi^{*}\right)$ and the lowest ${ }^{1}\left(\mathrm{n}_{\mathrm{A}} \pi^{*}\right)$ singlet excited states have been characterized by means of CASPT2//CASSCF computations. The obtained results match with the main photophysical properties experimentally reported: the lack of fluorescence and

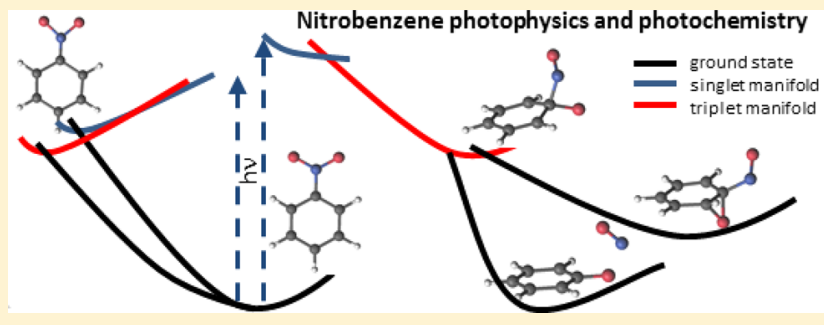
phosphorescence emission is justified by the presence of accessible conical intersections and intersystem crossing regions between, respectively, the ${ }^{1}\left(\mathrm{n}_{\mathrm{A}} \pi^{*}\right)$ and ${ }^{3}\left(\mathrm{n}_{\mathrm{A}} \pi^{*}\right)$ states and the ground state, while the high triplet quantum yield is attributable to the strong coupling between the ${ }^{1}\left(\mathrm{n}_{\mathrm{A}} \pi^{*}\right)$ and ${ }^{3}\left(\pi_{\mathrm{O}} \pi^{*}\right)$ states along the main decay path of the former. Two not previously reported singlet-triplet crossing regions, termed $(\mathrm{T} 1 / \mathrm{S} 0)_{\text {stc-NO }}$ and $(\mathrm{T} 1 / \mathrm{S} 0)_{\text {stc-ep }}$, have been here documented, from which the ground state can decay toward NO and phenoxy radical production and toward the formation of an epoxide ring structure, respectively. A possible mechanism leading to the photoisomerization of the nitro into the nitrite group, believed to be a key step in the photodegradation of nitrobenzene, has been proposed, based on the geometrical deformation recorded along the decay path leading from the ${ }^{1}\left(\mathrm{n}_{\mathrm{A}} \pi^{*}\right)$ state back to the original ground state through a conical intersection characterized by a significant shortening of the carbon-nitrogen bond.

\section{INTRODUCTION}

Nitrobenzene is the smallest nitroaromatic compound, is a common environmental pollutant normally produced in urban atmospheres during incomplete combustion, and is an ingredient in energetic explosives. ${ }^{1,2}$ Regarding the system's photophysics, NB is characterized by broad absorption spectra recorded in both solution and the gas-phase $e^{3,4}$ and by the almost lack of fluorescent and phosphorescent emissions. Terazima and co-workers have studied the photodynamics of the system in ethanol after excitation into the $S_{1}$ state using the picosecond time-resolved transient grating method and the population grating technique. ${ }^{5,7}$ Two main results have emerged from their works. First, most of the $S_{1}$ population will decay to the triplet manifold, as proven by the particularly high value of the triplet quantum yield, equal to 0.8 . Such a feature of the system was previously reported by Hurley et al., who measured a somehow lower but still significantly high value of the triplet quantum yield $(0.67) .{ }^{6}$ Second, the lowest triplet excited state is characterized by the significantly short lifetime of 480 ps. More generally, three lifetimes have been recorded in their works: $100 \mathrm{fs}$, explained as an $S_{1}$-intrastate relaxation; $6 \mathrm{ps}$, attributed to the decay from the $S_{1}$ to the triplet manifold; and the $480 \mathrm{ps}$ lifetime of $\mathrm{T}_{1}$.
Theoretically, a thoughtful work mainly performing rigid scans along selected coordinates and critically evaluating the accuracy for the description of $\mathrm{NB}$ of different electronic structure methods (as ADC3, MOM-CCSD(T), EOM-CCSD, $\mathrm{DFT} / \mathrm{MRCI}$, and CASSCF/NEVPT2) has been recently published by Dreuw, Marian, and co-workers. ${ }^{8}$ According to their results, the $100 \mathrm{fs}$ is due to decay back to the original ground state through a conical intersection $(\mathrm{CI})$ between $S_{1}$ and $S_{0}$ mainly characterized by the shortening of the ONO angle, which can be reached by surmounting an energy barrier from the $S_{1}$ minimum. The high triplet quantum yield associated with the 6 ps transfer from $S_{1}$ to the triplet manifold is explained by the degeneracy in energy together with a high value of the spin-orbit coupling (SOC) that characterized the $S_{1}$ and $T_{2}$ states at the $S_{1}$ minimum. Finally, the relaxation from the triplet states to the ground state is attributed to an accessible singlet-triplet crossing region (STC) between the $\mathrm{T}_{1}$ and $\mathrm{S}_{0}$ states, whose structure is characterized by a value of the ONCO dihedral angle equal to around $65-70^{\circ}$, which consequently determines the breaking of the molecule's planarity.

Received: November 24, 2016

Published: April 24, 2017 
Regarding NB photochemistry, three main photodegradation processes have been recorded under 220-320 nm exposure (5.63-3.87 eV), leading to $\mathrm{NO}, \mathrm{NO}_{2}$, and O. ${ }^{9}$ Among those photoproducts, $\mathrm{NO}_{2}$ has been reported to be the one produced in highest quantity. In particular, Galloway et al. using vacuumultraviolet photoionization molecular-beam mass spectrometry and Lin et al. employing multimass ion imaging technique have determined positive ratios between the $\mathrm{NO}_{2}$ and $\mathrm{NO}$ formation at different wavelengths, observing in both cases an increase of the ratio at higher excitation energies. ${ }^{9,10}$ Despite the reported $\mathrm{NO}_{2}$ higher production, Zewail and co-workers have concluded using ultrafast electronic diffraction that the main photoproduct obtained after $8.8 \pm 2.2$ ps with $266.7 \mathrm{~nm}$ excitation $(4.64 \mathrm{eV})$ is NO. ${ }^{11}$ This result can be explained by assuming that $\mathrm{NO}$ is the only photoproduct that can be formed directly in the excited states, while $\mathrm{NO}_{2}$ and $\mathrm{O}$ are produced after decay back to the ground state through a mechanism involving first the photoisomerization of the nitro group into a nitrite group (which constitutes the actual photoreaction) and a subsequently thermally activated bond breaking. ${ }^{12}$

The latter process can also lead to NO, which can then be obtained along two different paths. In agreement with such a hypothesis is the recorded bimodal distribution of the translational energy of the NO products, which naturally suggests the presence of two mechanisms of formation. The result has been obtained by Lin et al., ${ }^{10}$ who have also determined that the fast component in the translational energy distribution becomes smaller as the photolysis wavelengths increase, and in the paper of Suits and co-workers, ${ }^{13}$ where the slow and fast NO molecules have been further characterized to have low and high rotational excitation, respectively. In the latter work, both the slow and the fast products are believed to be formed through the photoisomerization of the nitro into the nitrite group, and the difference is to be found in the photoisomerization mechanism: the slow component is associated with a roaming-type mechanism taking place in the ground state, while the high translational molecules are the result of a photoisomerization mediated by the formation of an oxaziridine ring along the triplet manifold. Roaming reactions form a new class of mechanisms not contemplated in transition state theory, where the molecule undergoes partial dissociation to radical fragments by simple bond fission and may deviate substantially from the minimum energy path. ${ }^{13-15}$ The mechanism involving triplet states has been also proposed by Lin et al. and by Zewail and co-workers, ${ }^{10,11}$ and has been found to be the main photoisomerization mechanism in other nitroaromatic compounds, such as nitronaphthalene. ${ }^{16}$

In the present contribution, the photophysics and photochemistry of the title molecule have been studied by means of the CASPT2//CASSCF protocol, used in the framework of the so-called "photochemical reaction path approach". ${ }^{17}$ For the first time, the decay paths of the excited states of NB have been described by computing minimum energy paths, allowing the relaxation of all possible degrees of freedom of the molecule and so obtaining the unconstrained evolution of the system. Both decay from the brightest ${ }^{1}\left(\mathrm{~L}_{\mathrm{a}} \pi \pi^{*}\right)$ excited state and the lower-lying ${ }^{1}\left(\mathrm{n}_{\mathrm{A}} \pi^{*}\right)$ state have been characterized in detail. The results nicely rationalize all the main experimental data on the photophysics of the system, identifying not previously reported decay paths along both the singlet and triplet manifold. The rich photochemistry of NB has also been addressed, identifying two STC regions leading to different photoproducts. Finally, a possible explanation of the proposed photoisomerization roaming mechanism proposed by the imaging study of Suits and co-workers ${ }^{13}$ has been hypothesized on the basis of the main geometrical distortion characterizing the here documented CI and STC regions connecting the excited state manifold with the ground state.

\section{METHODS}

The present study has been performed employing the welltested CASPT2//CASSCF methodology ${ }^{18-20}$ as implemented in the MOLCAS 8 software. $^{21}$ Unless otherwise stated, optimized structures and minimum energy paths (MEPs) have been calculated at the multiconfigurational CASSCF level, while the final energies at the obtained geometries have been computed using the second-order multiconfigurational CASPT2 method, to take into account the dynamic correlation effects. Two optimizations of the ground state and one MEP computation have been performed at the CASPT2 level, numerically evaluating the required gradients. For all computations, no restrictions to the symmetry of the molecule have been imposed ( $C_{1}$ symmetry), and all degrees of freedom have been taken into account. The basis set of atomic natural orbital (ANO) of L-type contracted to C,N $[4 s, 3 p, 1 d] / H[2 s 1 p]$ has been employed. ${ }^{22,23}$

An active space composed of 14 active electrons distributed in 11 active orbitals has been used in all the final vertical calculations [CASSCF- $(14,11)]$. As shown in Figure S1 of the Supporting Information (SI), the selected active space takes into account both the $\pi$ nature of the system and the lone pairs of the oxygen atoms. Due to the computational costs associated with such an extended active space, different reduced active spaces have been used in the optimization procedures, depending on the state under analysis. Such a strategy was previously proved successful for different systems. ${ }^{16,24,25}$ To evaluate the photoreactivity of the system, a larger active space of 16 electrons in 13 orbitals has been used (see Photodegradation section). Within the CASPT2 calculations, an imaginary level-shift correction of 0.2 au has been used to minimize the effects of possible intruder states.

The CASPT2 standard zeroth-order Hamiltonian has been used as originally implemented. ${ }^{18}$ The core orbitals have been frozen in the CASPT2 calculations. Such a CASPT2 approach has been validated in many different studies on organic molecules, providing a correct prediction, description, and interpretation of photophysical experimental data. ${ }^{26-29}$

The search for the evolution of the excited states has been performed by means of MEP calculations, ${ }^{30,31}$ using massweighted coordinates. The technique provides the steepest descendent path, in which each step is built by the minimization of the energy on a hyperspherical cross section, whose radius has been chosen by the user, of the potential energy hypersurface centered on the initial geometry within a predefined radius. The importance and reliability of results obtained using such a computational tool have been proven in many different studies, which confirmed MEP calculations as a valuable procedure for the description of the photophysics and photochemistry of a molecule. ${ }^{17,32}$ In order to connect some important regions of the potential energy hypersurface $(\mathrm{PEH})$, linear interpolation of internal coordinate (LIIC) calculations have been performed. ${ }^{33}$ Conical intersections and singlettriplet crossing regions not obtained along MEP calculations have been computed by using the restricted Lagrange multipliers technique as included in the MOLCAS 8 package, in which the lowest-energy point is obtained under the 
restriction of degeneracy between the two considered states. $^{21,34}$ In the regions of the potential energy hypersurfaces where two or more states of different spin multiplicity are degenerate, the corresponding SOCs have been calculated, as described elsewhere. ${ }^{35}$ The Cholesky decomposition has been used to speed up the calculation of two-electron integrals. ${ }^{36,37}$

At all the optimized minima, the corresponding CASSCF frequencies have been computed to verify the character of the critical point.

\section{RESULTS AND DISCUSSION}

FC Geometry and Excited States. Starting from the ground state minimum found by González and co-workers at the B3LYP level, ${ }^{38}$ the NB ground state has been optimized using the $\operatorname{CASSCF}(14,11)$ method. The resulting structure displays shorter $\mathrm{NO}$ and $\mathrm{NC}$ bond lengths with respect to ground state minima previously obtained employing different computational strategies and with respect to the experimental data obtained by Domenicano et al. performing electron diffraction measurements (see Figure S4). ${ }^{39}$ The NB ground state structure has then been optimized at the CASPT2 $(14,11)$ level, and the resulting structure, hereafter ${ }^{1}(\mathrm{gs})_{\min }$, is in much better agreement with the available experimental and theoretical data (see Figure 4 and S4).

The ${ }^{1}(\mathrm{gs})_{\min }$ structure has been optimized computing a single root. In that way, the two oxygen lone pairs (orbital $\mathrm{H}-3$ and $\mathrm{H}-4$, see Figure S1) among the active orbitals for the characterization of the different critical points, do not remain in the active space, and instead two $\sigma$ orbitals appear (see Figure S1). To keep the oxygen lone pairs in the active space the ground state optimization has to be performed including excited states that involve those lone pairs, so as to force their presence in the active space. In order to test the influence of the lone pairs in the optimization, from the ${ }^{1}(\mathrm{gs})_{\min }$ minimum, a new CASPT2 $(14,11)$ ground state minimization has been performed with three roots. The resulting structure, hereafter ${ }^{1}(\mathrm{gs})_{\min -\mathrm{n}}$ (see Figure S5), displays similar geometrical parameters to the ${ }^{1}(\mathrm{gs})_{\min }$ minimum but is no longer planar, the nitro group being out of the plane of the ring $\left(\mathrm{C}_{6} \mathrm{C}_{1} \mathrm{~N}_{7} \mathrm{O}_{8}\right.$ dihedral angle equal to $\left.17.14^{\circ}\right)$. The computation of numerical CASPT2 frequencies at the ${ }^{1}(\mathrm{gs})_{\min }$ and ${ }^{1}(\mathrm{gs})_{\min -\mathrm{n}}$ minima have resulted in two imaginary frequencies (i47.83 and $i 35.17 \mathrm{~cm}^{-1}$ ) and three imaginary frequencies (i2102.01, i826.39, and i302.39 $\mathrm{cm}^{-1}$ ), respectively. The absolute values of the two imaginary CASPT2 frequencies are indeed very low, and consequently the ${ }^{1}(\mathrm{gs})_{\min }$ structure can be considered a true minimum. The same cannot be said for the ${ }^{1}(\mathrm{gs})_{\min -\mathrm{n}}$ geometry, where imaginary CASPT2 frequencies with non-negligible absolute values have been computed. For that reason and since all previous computational studies have characterized a planar ground state equilibrium structure (see Figure S4), we have decided to describe the photoresponse of the system from the ${ }^{1}(\mathrm{gs})_{\min }$ minimum.

At the ${ }^{1}(\mathrm{gs})_{\min }$ structure, five singlet and five triplet low-lying states have been computed so as to cover the energy region excitable under UVA and UVB exposure. The two lowest singlet states, hereafter ${ }^{1}\left(\mathrm{n}_{\mathrm{A}} \pi^{*}\right)$ and ${ }^{1}\left(\mathrm{n}_{\mathrm{B}} \pi^{*}\right)$, have both $\mathrm{n} \pi^{*}$ character and are mainly localized on the nitro group (see Figure S2). Despite different studies on NB having been performed after excitation into the ${ }^{1}\left(\mathrm{n}_{\mathrm{A}} \pi^{*}\right)$ state, the latter is actually dark at the $C_{2 v}$ structure of the planar ${ }^{1}(\mathrm{gs})_{\min }$ geometry. This apparent discordancy is explained by the low rotational barrier along the $\mathrm{CN}$ bond, which explains that the average $\mathrm{C}_{6} \mathrm{C}_{1} \mathrm{~N}_{7} \mathrm{O}_{8}$ dihedral angle experimentally reported by Domenicano et al. in gas phase is equal to $13^{\circ}$, breaking the $C_{2 v}$ symmetry of the planar structure. ${ }^{39}$

The two higher singlet states have $\pi \pi^{*}$ nature, and will be named ${ }^{1}\left(\mathrm{~L}_{\mathrm{b}} \pi \pi^{*}\right)$ and the ${ }^{1}\left(\mathrm{~L}_{\mathrm{a}} \pi \pi^{*}\right)$ state, respectively. The ${ }^{1}\left(\mathrm{~L}_{\mathrm{a}} \pi \pi^{*}\right)$ state is commonly reported in the literature as a charge transfer state from the benzene to the nitro group and in fact is mainly described by a single excitation from the HOMO $(\mathrm{H})$ orbital, which is localized on the ring, to the LUMO $(\mathrm{L})$, which is localized on the nitro group. The ${ }^{1}\left(\mathrm{~L}_{\mathrm{b}} \pi \pi^{*}\right)$ state is described by the minus linear combination of the $\mathrm{H} \rightarrow \mathrm{L}+1$ (22\%) and $\mathrm{H}-1 \rightarrow \mathrm{L}(22 \%)$ configurations. Among the singlet states, the ${ }^{1}\left(\mathrm{~L}_{\mathrm{a}} \pi \pi^{*}\right)$ is by far the brightest, with the oscillator strength associated with the electronic transition from the ground to the ${ }^{1}\left(\mathrm{~L}_{\mathrm{a}} \pi \pi^{*}\right)$ state being two orders of magnitude bigger than the oscillator strengths for the transitions to the remaining states (see Table 1 ).

Table 1. CASPT2//CASSCF $(14,11)$ Calculated Vertical Excitation Energies at the ${ }^{1}(\mathrm{gs})_{\min }\left(E_{\mathrm{VA}}, \mathrm{eV}\right)$ for the Lowest Valence Singlet and Spin Forbidden Triplet Excited States ${ }^{a}$

\begin{tabular}{lccc}
\multicolumn{1}{c}{ state } & $E_{\mathrm{VA}}(\mathrm{eV})$ & $f$ & $\mu(\mathrm{D})$ \\
$\mathrm{S}_{0}$ gs & 0.00 & & 4.16 \\
$\mathrm{~T}_{1}{ }^{3}\left(\mathrm{n}_{\mathrm{A}} \pi^{*}\right)$ & 3.15 & & 2.49 \\
$\mathrm{~T}_{2}{ }^{3}\left(\pi_{\mathrm{O}} \pi^{*}\right)$ & 3.30 & & 2.02 \\
$\mathrm{~S}_{1}{ }^{1}\left(\mathrm{n}_{\mathrm{A}} \pi^{*}\right)$ & 3.32 & 0.00000 & 2.37 \\
$\mathrm{~T}_{3}{ }^{3}\left(\mathrm{~L}_{\mathrm{a}} \pi \pi^{*}\right)$ & 3.71 & & 4.42 \\
$\mathrm{~T}_{4}{ }^{3}\left(\mathrm{n}_{\mathrm{B}} \pi^{*}\right)$ & 3.75 & & 2.44 \\
$\mathrm{~S}_{2}{ }^{1}\left(\mathrm{n}_{\mathrm{B}} \pi^{*}\right)$ & 3.84 & 0.00035 & 2.30 \\
$\mathrm{~T}_{5}{ }^{3}\left(\mathrm{~L}_{\mathrm{b}} \pi \pi^{*}\right)$ & 4.17 & & 4.87 \\
$\mathrm{~S}_{3}{ }^{1}\left(\mathrm{~L}_{\mathrm{b}} \pi \pi^{*}\right)$ & 4.37 & 0.00362 & 4.80 \\
$\mathrm{~S}_{4}{ }^{1}\left(\mathrm{~L}_{\mathrm{a}} \pi \pi^{*}\right)$ & 5.01 & 0.22473 & 7.22
\end{tabular}

${ }^{a_{T}}$ The computed dipole moments $(\mu, \mathrm{D})$ and the oscillator strengths ( $f$ ) for the singlet-singlet transitions computed at the CASSCF$(14,11)$ level are also included.

Regarding the triplet excitations, the two $\mathrm{n} \pi^{*}$ and two $\pi \pi^{*}$ states corresponding to the above-described singlet states have been characterized (i.e., the ${ }^{3}\left(\mathrm{n}_{\mathrm{A}} \pi^{*}\right),{ }^{3}\left(\mathrm{n}_{\mathrm{B}} \pi^{*}\right),{ }^{3}\left(\mathrm{~L}_{\mathrm{a}} \pi \pi^{*}\right)$, and ${ }^{3}\left(\mathrm{~L}_{\mathrm{b}} \pi \pi^{*}\right)$ states $)$. An additional triplet $\pi \pi^{*}$ state localized on the nitro group has been computed (see Figure S3), hereafter named ${ }^{3}\left(\pi_{\mathrm{O}} \pi^{*}\right)$. The latter and the ${ }^{1}\left(\mathrm{n}_{\mathrm{A}} \pi^{*}\right)$ states are degenerate at the FC region and display a high SOC value, equal to $76.75 \mathrm{~cm}^{-1}$.

On the basis of the computed vertical excitation energies, the lowest triplet state at the FC region is the ${ }^{3}\left(\mathrm{n}_{\mathrm{A}} \pi^{*}\right)$, followed by the ${ }^{3}\left(\pi_{\mathrm{O}} \pi^{*}\right)$ state, $0.15 \mathrm{eV}$ above. According to the calculations performed by Dreuw, Marian, and co-workers using different electronic structure methods on a B2PLYP optimized structure (see Figure S4), the reverse ordering of these states (i.e., ${ }^{3}\left(\pi_{\mathrm{O}} \pi^{*}\right)$ lower than the ${ }^{3}\left(\mathrm{n}_{\mathrm{A}} \pi^{*}\right)$ state $)$ has been obtained, although a small energy gap between them of $0.2-0.5 \mathrm{eV}$ has been described. In particular, at the NEVPT2 $(14,11)$ level, the two triplet states are separated by only $0.18 \mathrm{eV}$. For the sake of comparison, the triplet states at the ground-state B2PLYP optimized structure presented by Dreuw, Marian, and coworkers have been here computed at the CASPT2 $(14,11)$ level state-averaging over both two and five roots and at the CASPT2 $(18,13)$ level over two roots, expanding the 14,11 active space with two $\sigma$ orbitals on the nitrogen-oxygen bonds. In all cases, the ${ }^{3}\left(\mathrm{n}_{\mathrm{A}} \pi^{*}\right)$ state has been found to be the lowest 

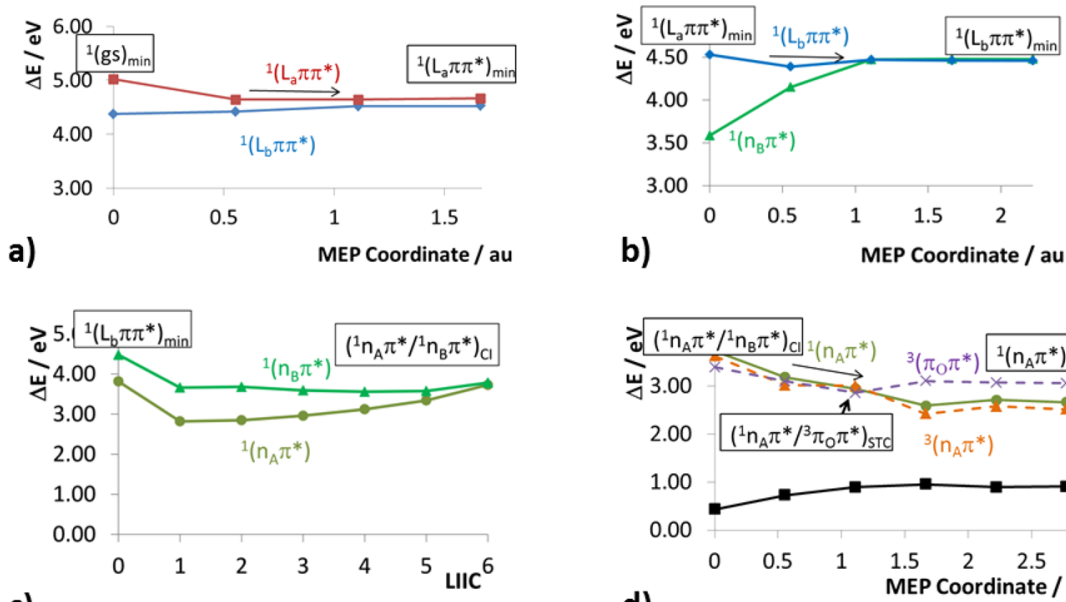

c)

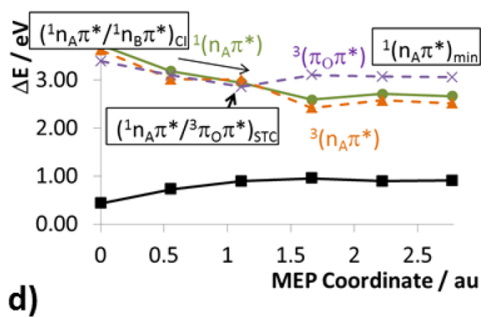

Figure 1. Potential energy hypersurfaces of the most photophysically and photochemically relevant electronic states along the computed paths on the singlet manifold: (a) MEP on the ${ }^{1}\left(\mathrm{~L}_{\mathrm{a}} \pi \pi^{*}\right)$ state from the ${ }^{1}(\mathrm{gs})_{\min }$ structure; (b) MEP on the ${ }^{1}\left(\mathrm{~L}_{\mathrm{b}} \pi \pi^{*}\right)$ from the ${ }^{1}\left(\mathrm{~L}_{\mathrm{a}} \pi \pi^{*}\right)_{\min }$ minimum; (c) LIIC from the ${ }^{1}\left(\mathrm{~L}_{\mathrm{b}} \pi \pi^{*}\right)_{\min }$ to the $\left({ }^{1} \mathrm{n}_{\mathrm{A}} \pi^{* / 1} \mathrm{n}_{\mathrm{B}} \pi^{*}\right)_{\mathrm{CI}}$ conical intersection; (d) MEP on the ${ }^{1}\left(\mathrm{n}_{\mathrm{A}} \pi^{*}\right)$ state from the $\left({ }^{1} \mathrm{n}_{\mathrm{A}} \pi^{* / 1} \mathrm{n}_{\mathrm{B}} \pi^{*}\right)_{\mathrm{CI}}$ geometry.

Table 2. CASPT2//CASSCF $(14,11)$ Computed Energies (eV) for the Most Relevant Singlet and Triplet States of Nitrobenzene at Different Critical Points ${ }^{a}$

\begin{tabular}{|c|c|c|c|c|c|c|c|}
\hline \multirow[b]{2}{*}{ structure } & \multicolumn{7}{|c|}{ State } \\
\hline & Gs & ${ }^{1}\left(\mathrm{n}_{\mathrm{A}} \pi^{*}\right)$ & ${ }^{1}\left(\mathrm{n}_{\mathrm{B}} \pi^{*}\right)$ & ${ }^{1}\left(\mathrm{~L}_{\mathrm{b}} \pi \pi^{*}\right)$ & ${ }^{1}\left(\mathrm{~L}_{\mathrm{a}} \pi \pi^{*}\right)$ & ${ }^{3}\left(\mathrm{n}_{\mathrm{A}} \pi^{*}\right)$ & ${ }^{3}\left(\pi_{\mathrm{O}} \pi^{*}\right)$ \\
\hline${ }^{1}(\mathrm{gs})_{\min }$ & 0.00 & $3.32(3.56)^{b}$ & 3.84 & 4.37 & 5.01 & $3.15(3.32)^{b}$ & $3.30(3.39)^{b}$ \\
\hline${ }^{1}\left(\mathrm{~L}_{\mathrm{a}} \pi \pi^{*}\right)_{\min }$ & 0.22 & 3.38 & 3.59 & 4.52 & 4.66 & 3.27 & 3.32 \\
\hline${ }^{1}\left(\mathrm{~L}_{\mathrm{b}} \pi \pi^{*}\right)_{\min }$ & 0.47 & 3.82 & 4.48 & 4.46 & - & 3.63 & 3.87 \\
\hline$\left({ }^{1} \mathrm{n}_{\mathrm{A}} \pi^{*} /{ }^{1} \mathrm{n}_{\mathrm{B}} \pi^{*}\right)_{\mathrm{CI}}$ & 0.43 & 3.73 & 3.78 & - & - & 3.63 & 3.39 \\
\hline${ }^{1}\left(\mathrm{n}_{\mathrm{A}} \pi^{*}\right)_{\min }$ & 0.91 & 2.66 & 4.37 & - & - & 2.52 & 3.06 \\
\hline$\left({ }^{1} \mathrm{n}_{\mathrm{A}} \pi^{*} /{ }^{3} \pi_{\mathrm{O}} \pi^{*}\right)_{\mathrm{STC}}$ & 0.89 & 2.95 & 4.41 & - & - & 3.00 & 2.86 \\
\hline$\left({ }^{1} \mathrm{n}_{\mathrm{A}} \pi^{*} / \mathrm{gs}\right)_{\mathrm{Cl}}$ & 3.13 & 3.20 & - & - & - & - & - \\
\hline${ }^{3}\left(\pi_{\mathrm{O}} \pi^{*}\right)_{\min }$ & 0.43 & 2.66 & - & - & - & 2.50 & 2.84 \\
\hline$\left({ }^{3} \pi_{\mathrm{O}} \pi^{*} /{ }^{3} \mathrm{n}_{\mathrm{A}} \pi^{*}\right)_{\mathrm{CI}}$ & 0.36 & 3.04 & - & - & - & 2.91 & 2.91 \\
\hline${ }^{3}\left(\mathrm{n}_{\mathrm{A}} \pi^{*}\right)_{\min }$ & 0.85 & 2.75 & - & - & - & 2.61 & 3.06 \\
\hline$\left({ }^{3} \mathrm{n}_{\mathrm{A}} \pi^{*} / \mathrm{gs}\right)_{\mathrm{STC}}$ & 2.65 & 2.99 & - & - & - & 2.71 & 3.87 \\
\hline
\end{tabular}

${ }^{a}$ All the reported values are referred to the ground state optimized geometry, ${ }^{1}(\mathrm{gs})_{\min }$. The energies have been obtained state-averaging over six singlet and five triplet roots. ${ }^{b}$ Energies obtained state-averaging over two singlet and two triplet roots.

triplet state of the system, closely followed by the ${ }^{3}\left(\pi_{\mathrm{O}} \pi^{*}\right)$ state, so confirming the ordering here obtained. Another possible source of difference causing the inverted energy ordering of the two lowest triplet excited states could be the different basis sets employed: the ANO-L C,N $[4 s, 3 p, 1 d] /$ $\mathrm{H}[2 \mathrm{~s} 1 \mathrm{p}]$ basis set has been here used, while the def2-TZVP was employed by Dreuw, Marian, and co-workers. The latter is significantly larger than the former. In order to evaluate the effect of the basis set dimension on the energy ordering of the triplet states, a computation at the ground-state B2PLYP optimized structure has been performed using the ANO-L $\mathrm{C}, \mathrm{N}[5 \mathrm{~s}, 4 \mathrm{p}, 2 \mathrm{~d}, 1 \mathrm{f}] / \mathrm{H}[4 \mathrm{~s} 2 \mathrm{p} 1 \mathrm{~d}]$ basis set. Again the ${ }^{3}\left(\mathrm{n}_{\mathrm{A}} \pi^{*}\right)$ states is the lowest triplet root, although the ${ }^{3}\left(\pi_{\mathrm{O}} \pi^{*}\right)$ state is now only $0.06 \mathrm{eV}$ above.

Since the two states are very close in energy, being actually degenerate accordingly to some levels of theory, it is difficult to say the final word with respect to the exact energy ordering in the system around the ground state minimum. As shown in the remaining part of the paper, the exact energy ordering of the two lowest triplet states at the ground state geometry is not expected to be of strong relevance for the photoresponse of the system.
The obtained results on the excited states of the system at the FC region are reported in Table 1, while in Tables S1 and S2 the comparison with the available experimental and theoretical data showed a reasonable agreement among them.

Main Decay Path from the Bright ${ }^{1}\left(\mathrm{~L}_{\mathrm{a}} \pi \pi^{*}\right)$ State. On the basis of the computed oscillator strengths at the ${ }^{1}(\mathrm{gs})_{\min }$ (see Table 1) under UV absorption most of the population will reach the ${ }^{1}\left(\mathrm{~L}_{a} \pi \pi^{*}\right)$ state. In order to study its evolution, a MEP computation along this state has been performed starting at the ${ }^{1}(\mathrm{gs})_{\min }$ geometry.

Since the ${ }^{1}\left(\mathrm{~L}_{\mathrm{a}} \pi \pi^{*}\right)$ state is the energetically highest at the FC region among all states characterized in Table 1, all those states have been computed along the main decay path from the ${ }^{1}\left(\mathrm{~L}_{a} \pi \pi^{*}\right)$ state, performing CASSCF state-averaging calculations over six singlet and five triplet states.

A CASSCF $(6,6)$ active space composed of the $\mathrm{H}-5, \mathrm{H}-1$, H, L, L +1 , and L +2 orbitals (see Figure S1) has been used in the aforementioned MEP to reduce the computational effort by decreasing the number of Slater determinants in which the electronic wave functions are expanded and avoiding the need for computing the lower ${ }^{1}\left(\mathrm{n}_{\mathrm{B}} \pi^{*}\right)$ and ${ }^{1}\left(\mathrm{n}_{\mathrm{A}} \pi^{*}\right)$ states, which are not required for describing the evolution of the higher ${ }^{1}\left(\mathrm{~L}_{\mathrm{a}} \pi \pi^{*}\right)$ 
state. As shown in Figure 1a, the system on the ${ }^{1}\left(\mathrm{~L}_{\mathrm{a}} \pi \pi^{*}\right)$ state evolves toward a minimum structure, hereafter denoted as ${ }^{1}\left(\mathrm{~L}_{\mathrm{a}} \pi \pi^{*}\right)_{\min }$, that is close in energy to the ${ }^{1}\left(\mathrm{~L}_{\mathrm{b}} \pi \pi^{*}\right)$ state and from which consequently part of the population can pass to the ${ }^{1}\left(\mathrm{~L}_{\mathrm{b}} \pi \pi^{*}\right)$ state (see Table 2$)$. The latter can further decay following the MEP obtained along the ${ }^{1}\left(\mathrm{~L}_{\mathrm{b}} \pi \pi^{*}\right)$ hypersurface from the ${ }^{1}\left(\mathrm{~L}_{\mathrm{a}} \pi \pi^{*}\right)_{\min }$ point, which, as depicted in Figure $1 \mathrm{~b}$, leads to the ${ }^{1}\left(\mathrm{~L}_{\mathrm{b}} \pi \pi^{*}\right)_{\min }$ minimum that is a conical intersection between the ${ }^{1}\left(\mathrm{~L}_{\mathrm{b}} \pi \pi^{*}\right)$ and the ${ }^{1}\left(\mathrm{n}_{\mathrm{B}} \pi^{*}\right)$ states.

The MEP on ${ }^{1}\left(\mathrm{~L}_{b} \pi \pi^{*}\right)$ from the ${ }^{1}\left(\mathrm{~L}_{\mathrm{a}} \pi \pi^{*}\right)_{\min }$ geometry has been obtained with a $\operatorname{CASSCF}(6,6)$ active space including the $\mathrm{H}-2, \mathrm{H}-1, \mathrm{H}, \mathrm{L}, \mathrm{L}+1$, and $\mathrm{L}+2$ orbitals. From the ${ }^{1}\left(\mathrm{~L}_{\mathrm{b}} \pi \pi^{*}\right)_{\text {min }}$ structure a $\operatorname{CASSCF}(8,6)$ MEP (including the $\mathrm{H}-$ $4, \mathrm{H}-3, \mathrm{H}-1, \mathrm{H}, \mathrm{L}$, and $\mathrm{L}+1$ orbitals $)$ on the ${ }^{1}\left(\mathrm{n}_{\mathrm{B}} \pi^{*}\right)$ state fails to converge. The calculation initially evolves toward a region in which the ${ }^{1}\left(\mathrm{n}_{\mathrm{B}} \pi^{*}\right)$ and ${ }^{1}\left(\mathrm{n}_{\mathrm{A}} \pi^{*}\right)$ states get closer in energy, suggesting the presence of a nearby $\mathrm{CI}$ involving those states. A crossing region between them has been in fact characterized, hereafter called $\left({ }^{1} \mathrm{n}_{\mathrm{A}} \pi^{*} /{ }^{1} \mathrm{n}_{\mathrm{B}} \pi^{*}\right)_{\mathrm{Cl}}$, and the possibility that the system can reach it has been evaluated performing a LIIC computation between the ${ }^{1}\left(\mathrm{~L}_{\mathrm{b}} \pi \pi^{*}\right)_{\min }$ and the $\left({ }^{1} \mathrm{n}_{\mathrm{A}} \pi^{*} /{ }^{1} \mathrm{n}_{\mathrm{B}} \pi^{*}\right)_{\mathrm{CI}}$ structures (see Figure 1c). Along this computed path, an upper bound of the energy barrier needed to be overcome in order to evolve toward the CI has been found to be $0.22 \mathrm{eV}$, so according to this a decay from the ${ }^{1}\left(\mathrm{n}_{\mathrm{B}} \pi^{*}\right)$ to the ${ }^{1}\left(\mathrm{n}_{\mathrm{A}} \pi^{*}\right)$ state through the $\left({ }^{1} \mathrm{n}_{\mathrm{A}} \pi^{*} /{ }^{1} \mathrm{n}_{\mathrm{B}} \pi^{*}\right)_{\mathrm{CI}}$ is highly plausible. The ${ }^{1}\left(\mathrm{n}_{\mathrm{A}} \pi^{*}\right)$ state can then evolve to a minimum structure, ${ }^{1}\left(\mathrm{n}_{\mathrm{A}} \pi^{*}\right)_{\min }$ as shown by the computed $\operatorname{CASSCF}(14,11)$ MEP from the $\left({ }^{1} n_{\mathrm{A}} \pi^{*} /{ }^{1} \mathrm{n}_{\mathrm{B}} \pi^{*}\right)_{\mathrm{CI}}$ geometry (see Figure 1d).

Since no fluorescence emission has been experimentally reported, an efficient nonradiative decay must operate in order to bring the population from the ${ }^{1}\left(\mathrm{n}_{\mathrm{A}} \pi^{*}\right)_{\min }$ back to the ground state. A CI between the ${ }^{1}\left(\mathrm{n}_{\mathrm{A}} \pi^{*}\right)$ and the ground state, named $\left({ }^{1} n_{\mathrm{A}} \pi^{*} / \mathrm{gs}\right)_{\mathrm{Cl}}$, has been in fact located, which is accessible from the ${ }^{1}\left(\mathrm{n}_{\mathrm{A}} \pi^{*}\right)_{\min }$ through the surmounting of at most an energy barrier equal to $0.54 \mathrm{eV}$, as proven by the computation of the corresponding LIIC (see Figure 3a). Finally, the ground state from the $\left({ }^{1} n_{\mathrm{A}} \pi^{*} / \mathrm{gs}\right)_{\mathrm{CI}}$ CI can evolve back to the ${ }^{1}(\mathrm{gs})_{\min }$ structure.

As well as the above-described decay path, the system is also expected to populate the triplet manifold, as the high value of the experimentally measured triplet quantum yield strongly implies. Along the MEP from the $\left({ }^{1} n_{\mathrm{A}} \pi^{*} /{ }^{1} \mathrm{n}_{\mathrm{B}} \pi^{*}\right)_{\mathrm{CI}}$ on the ${ }^{1}\left(\mathrm{n}_{\mathrm{A}} \pi^{*}\right)$ state, both the ${ }^{3}\left(\mathrm{n}_{\mathrm{A}} \pi^{*}\right)$ and the ${ }^{3}\left(\pi_{\mathrm{O}} \pi^{*}\right)$ states are crossed. The ${ }^{1}\left(\mathrm{n}_{\mathrm{A}} \pi^{*}\right)$ and ${ }^{3}\left(\mathrm{n}_{\mathrm{A}} \pi^{*}\right)$ hypersurface remain degenerate almost along all the MEP, while the gap between the ${ }^{1}\left(\mathrm{n}_{\mathrm{A}} \pi^{*}\right)$ and ${ }^{3}\left(\pi_{\mathrm{O}} \pi^{*}\right)$ states is less than $0.10 \mathrm{eV}$ at one computed point before the surfaces cross. Nevertheless, the decay from the ${ }^{1}\left(\mathrm{n}_{\mathrm{A}} \pi^{*}\right)$ to the ${ }^{3}\left(\pi_{\mathrm{O}} \pi^{*}\right)$ state is expected to be much more efficient than the population of the ${ }^{3}\left(\mathrm{n}_{\mathrm{A}} \pi^{*}\right)$ hypersurface, since the SOC between the former states is much higher than that for the latter: 70.94 and $0.51 \mathrm{~cm}^{-1}$, respectively, at the second point $(1.1 \mathrm{au})$ of the ${ }^{1}\left(\mathrm{n}_{\mathrm{A}} \pi^{*}\right)$ MEP, hereafter $\left({ }^{1} \mathrm{n}_{\mathrm{A}} \pi^{*} /{ }^{3} \pi_{\mathrm{O}} \pi^{*}\right)_{\mathrm{STC}}$. This is as expected according to the El Sayed rules.

From the $\left({ }^{1} n_{\mathrm{A}} \pi^{*} /{ }^{3} \pi_{\mathrm{O}} \pi^{*}\right)_{\mathrm{STC}}$ structure, the $\operatorname{CASSCF}(14,11)$ MEP on the ${ }^{3}\left(\pi_{\mathrm{O}} \pi^{*}\right)$ state evolves to the ${ }^{3}\left(\pi_{\mathrm{O}} \pi^{*}\right)_{\min }$ geometry (Figure 2a). At the ${ }^{3}\left(\pi_{\mathrm{O}} \pi^{*}\right)_{\min }$ equilibrium structure, the ${ }^{3}\left(\mathrm{n}_{\mathrm{A}} \pi^{*}\right)$ state is still the $\mathrm{T}_{1}$ state. The system can pass to the lower ${ }^{3}\left(\mathrm{n}_{\mathrm{A}} \pi^{*}\right)$ state through an accessible conical intersection, $\left({ }^{3} \pi_{\mathrm{O}} \pi^{*} /{ }^{3} \mathrm{n}_{\mathrm{A}} \pi^{*}\right)_{\mathrm{Cl}}$, as proven by the very low energy barrier of

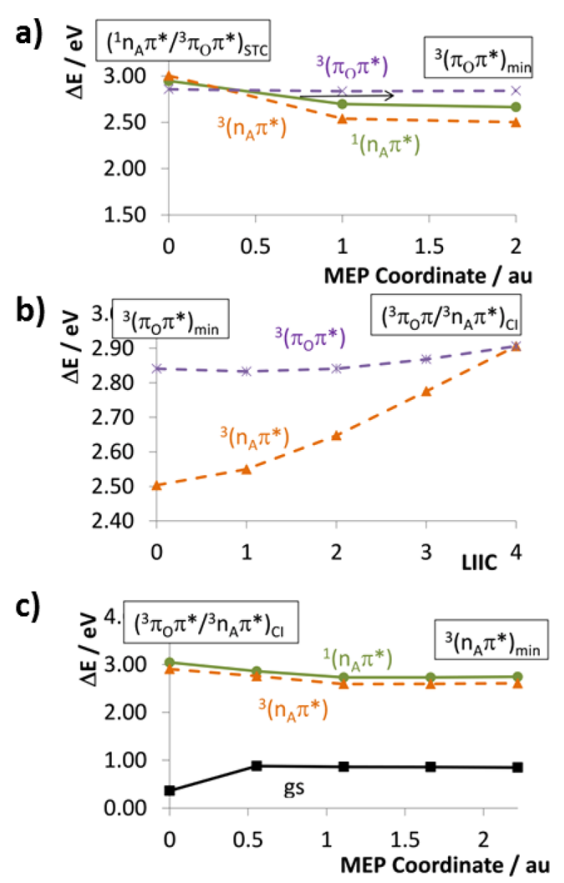

Figure 2. Potential energy hypersurfaces of the most photophysically and photochemically relevant electronic states along the computed paths on the triplet manifold: (a) MEP on the ${ }^{3}\left(\pi_{\mathrm{O}} \pi^{*}\right)$ state from the $\left({ }^{1} n_{\mathrm{A}} \pi^{* / 3} \pi_{\mathrm{O}} \pi^{*}\right)_{\text {STC }}$ singlet-triplet crossing region; (b) LIIC from the ${ }^{3}\left(\pi_{\mathrm{O}} \pi^{*}\right)_{\text {min }}$ to the $\left({ }^{3} \pi_{\mathrm{O}} \pi^{*} /{ }^{3} \mathrm{n}_{\mathrm{A}} \pi^{*}\right)_{\mathrm{CI}}$ conical intersection; (c) MEP on the ${ }^{3}\left(\mathrm{n}_{\mathrm{A}} \pi^{*}\right)$ state from the $\left({ }^{3} \pi_{\mathrm{O}} \pi^{*} /{ }^{3} \mathrm{n}_{\mathrm{A}} \pi^{*}\right)_{\mathrm{CI}}$ geometry.

$0.08 \mathrm{eV}$ resulting from the computed LIIC path (Figure $2 \mathrm{~b}$ ), from which the ${ }^{3}\left(\mathrm{n}_{\mathrm{A}} \pi^{*}\right)_{\min }$ minimum can be populated (Figure 2c). Again the lack of phosphorescence emission points to the presence of an efficient nonradiative decay process, found here in the presence of a STC region with the ground state, hereafter $\left({ }^{3} \mathrm{n}_{\mathrm{A}} \pi^{*} / \mathrm{gs}\right)_{\mathrm{STC}}$, separated from the ${ }^{3}\left(\mathrm{n}_{\mathrm{A}} \pi^{*}\right)_{\text {min }}$ structure by a $0.10 \mathrm{eV}$ energy barrier (Figure $3 \mathrm{~b}$ ). This STC region is expected to efficiently mediate decay to the ground state, with an SOC between the ${ }^{3}\left(\mathrm{n}_{\mathrm{A}} \pi^{*}\right)$ and the ground state of 73.28 $\mathrm{cm}^{-1}$.

The geometries of all the obtained critical points are depicted in Figures 4 and 5. A schematic representation of the described paths leading to the radiationless repopulation of the original ground state structure is presented in Figure 6.

Main Decay Path from the ${ }^{1}\left(n_{A} \pi^{*}\right)$ State. Since several experimental results have been obtained exciting NB into the ${ }^{1}\left(\mathrm{n}_{\mathrm{A}} \pi^{*}\right)$ state, such as the three lifetimes reported by Terazima and co-workers (100 fs, $6 \mathrm{ps}$, and $480 \mathrm{ps}){ }^{7}$ the evolution of the latter has been here studied from the ${ }^{1}(\mathrm{gs})_{\min }$ ground state minimum.

According to the data reported above in Table 1 and obtained optimizing the orbitals using a CASSCF stateaveraging procedure over six singlet and five triplet roots, at the ${ }^{1}(\mathrm{gs})_{\min }$ structure only the ${ }^{3}\left(\mathrm{n}_{\mathrm{A}} \pi^{*}\right)$ and the ${ }^{3}\left(\pi_{\mathrm{O}} \pi^{*}\right)$ states are lower in energy than the ${ }^{1}\left(\mathrm{n}_{\mathrm{A}} \pi^{*}\right)$. Consequently, we decided to follow the evolution of the latter state performing CASSCF state-averaging calculations over two singlet and two triplet states. As a first outcome, the energies at the ground state minimum of the ${ }^{1}\left(\mathrm{n}_{\mathrm{A}} \pi^{*}\right)$ and ${ }^{3}\left(\mathrm{n}_{\mathrm{A}} \pi^{*}\right)$ states both slightly increase by 0.24 and $0.17 \mathrm{eV}$, respectively, while the ${ }^{3}\left(\pi_{\mathrm{O}} \pi^{*}\right)$ remains almost constant (only $0.09 \mathrm{eV}$ energy rise) (see Table 2 and Table S3). Without changing the resulting energy ordering of the states, the reported energy shifts have as a main 


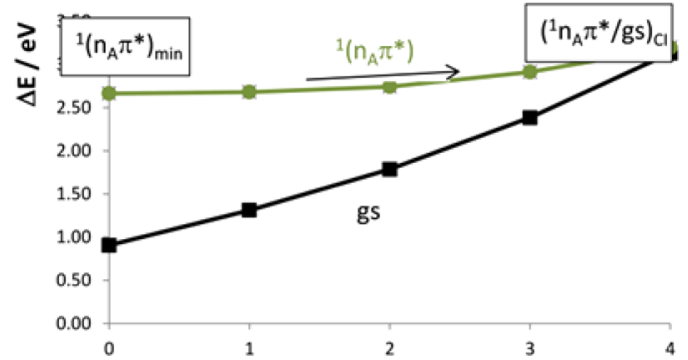

a)

LIIC

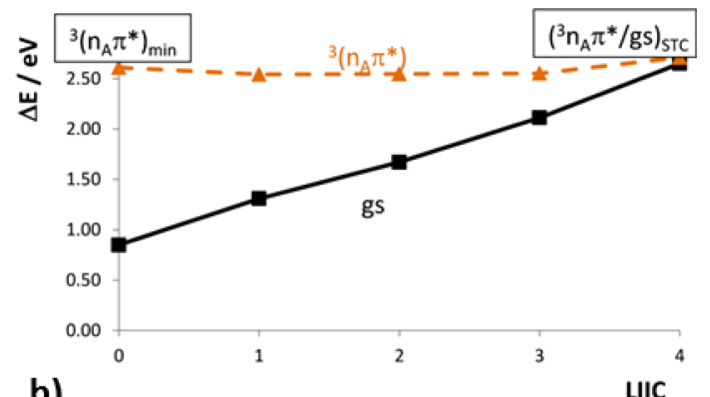

Figure 3. LIIC computations connecting the singlet and triplet manifold to the ground state: (a) LIIC from the ${ }^{1}\left(\mathrm{n}_{\mathrm{A}} \pi^{*}\right)_{\min }$ minimum to the $\left({ }^{1} \mathrm{n}_{\mathrm{A}} \pi^{*} /\right.$ gs $)_{\mathrm{CI}}$ (b) LIIC from the ${ }^{3}\left(\mathrm{n}_{\mathrm{A}} \pi^{*}\right)_{\min }$ minimum to the $\left({ }^{3} \mathrm{n}_{\mathrm{A}} \pi^{*} / \mathrm{gs}\right)_{\mathrm{STC}}$.
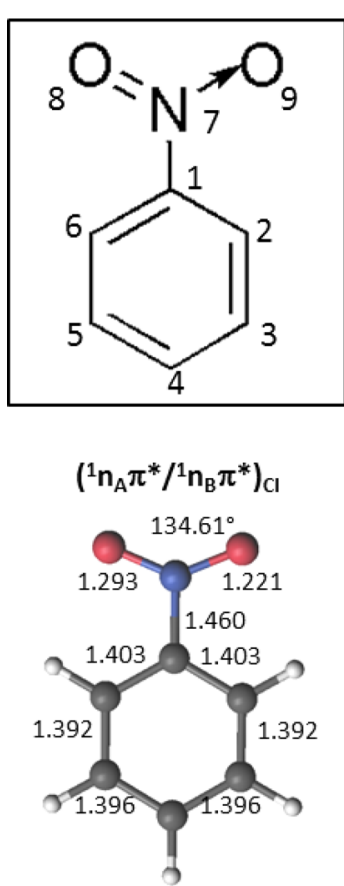
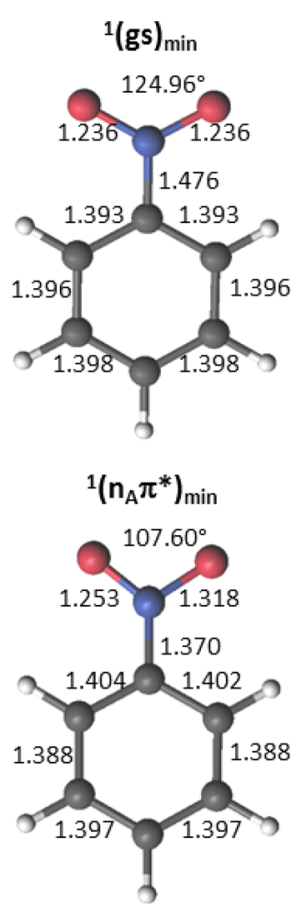

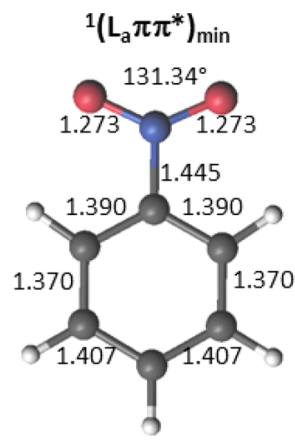

$\left({ }^{1} \mathrm{n}_{\mathrm{A}} \pi^{*} /{ }^{3} \pi_{\mathrm{O}} \pi^{*}\right)_{\mathrm{STC}}$

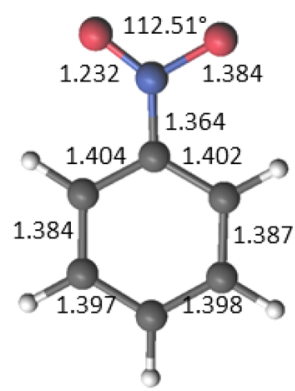

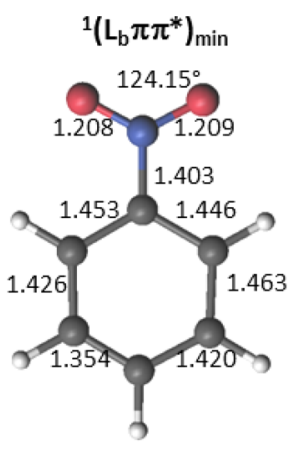

$\left({ }^{1} n_{A} \pi^{*} / g s\right)_{\mathrm{Cl}}$

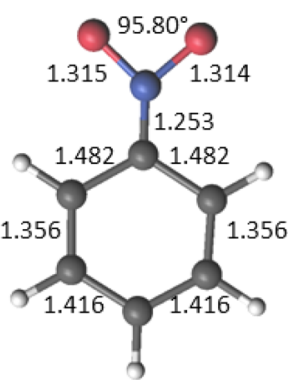

Figure 4. Minima, conical intersections, and singlet-triplet crossing regions characterized along the main decay path of the ${ }^{1}\left(\mathrm{~L}_{\mathrm{a}} \pi \pi^{*}\right)$ state on the singlet manifold. Selected bond lengths (in $\AA$ ) and angles (in deg) are also reported. In the inset is displayed the nitrobenzene structure and the atom labeling.
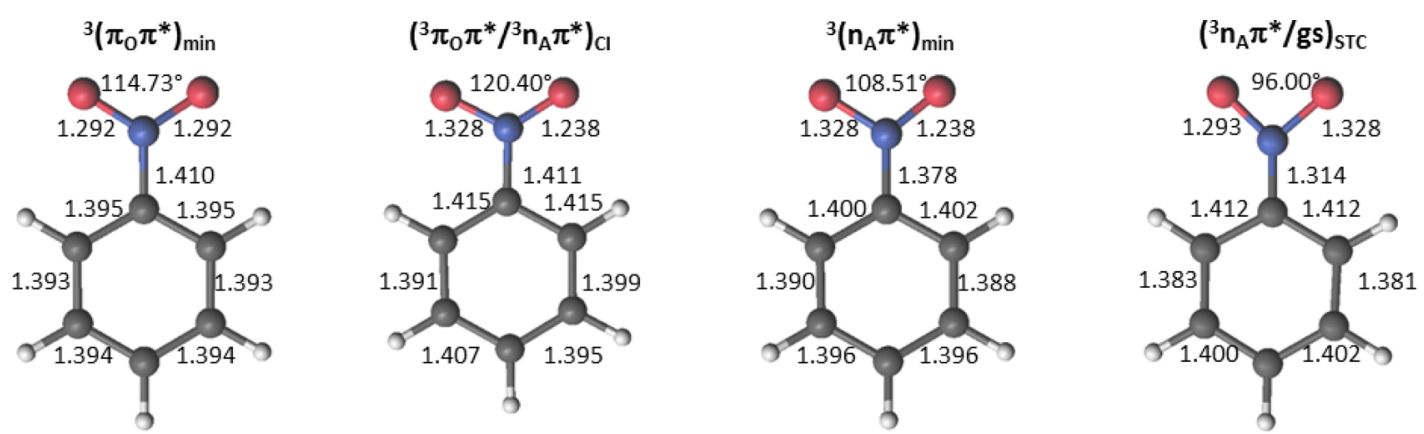

Figure 5. Minima, conical intersections, and singlet-triplet crossing regions characterized along the main decay path of the ${ }^{1}\left(\mathrm{~L}_{\mathrm{a}} \pi \pi^{*}\right)$ state on the triplet manifold. Selected bond lengths (in $\AA$ ) and angles (in deg) are also reported.

consequence that the ${ }^{1}\left(\mathrm{n}_{\mathrm{A}} \pi^{*}\right)$ and the ${ }^{3}\left(\pi_{\mathrm{O}} \pi^{*}\right)$ states are no longer degenerate at the ${ }^{1}(\mathrm{gs})_{\min }$ geometry. A decay from the ${ }^{1}\left(\mathrm{n}_{\mathrm{A}} \pi^{*}\right)$ to the ${ }^{3}\left(\pi_{\mathrm{O}} \pi^{*}\right)$ state, predictable by the six-singlet fivetriplet CASSCF state-averaged results, is nevertheless still predicted in the two-singlet two-triplet models; as the states are close in energy ( $0.17 \mathrm{eV}$ energy gap), they are characterized by a high SOC $\left(63.81 \mathrm{~cm}^{-1}\right)$, and the ${ }^{3}\left(\pi_{\mathrm{O}} \pi^{*}\right)$ hypersurface is below the ${ }^{1}\left(\mathrm{n}_{\mathrm{A}} \pi^{*}\right)$ one, suggesting that the relaxation of the ${ }^{1}\left(\mathrm{n}_{\mathrm{A}} \pi^{*}\right)$ state will decay toward a STC region, a result that, as shown below, has been in fact obtained.

Performing MEP computations and LIIC paths, a similar photophysical evolution of the system on the ${ }^{1}\left(\mathrm{n}_{\mathrm{A}} \pi^{*}\right)$ state 


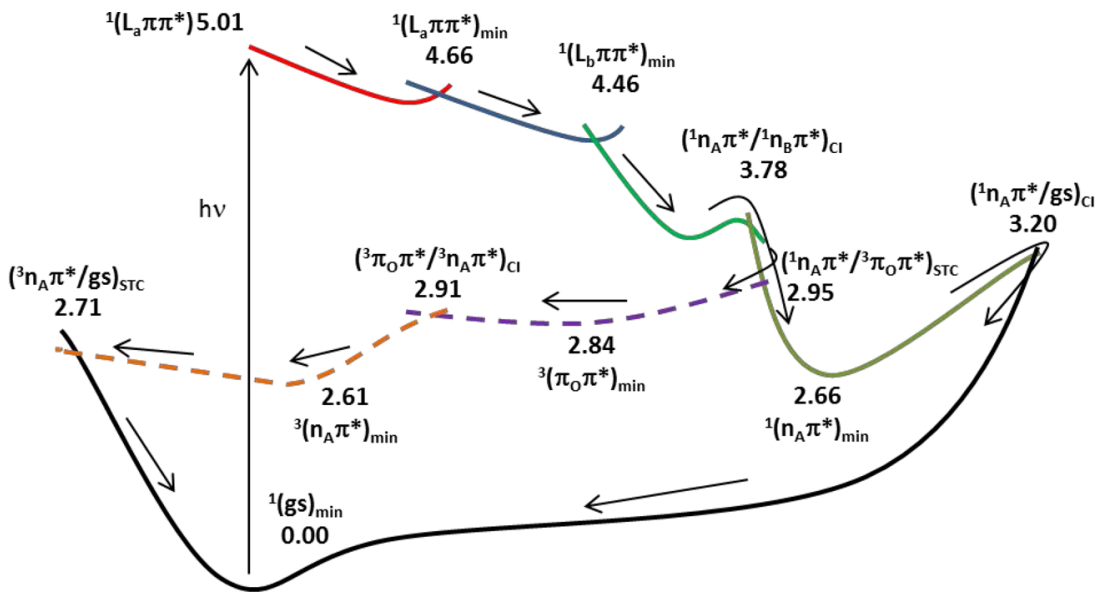

Figure 6. Schematic representation of the main decay paths that after excitation into the ${ }^{1}\left(\mathrm{~L}_{\mathrm{a}} \pi \pi^{*}\right)$ state evolve toward radiationless repopulation of the original ground state. Solid red, solid blue, solid green, solid olive-green, solid black, dashed purple, dashed orange lines indicate the evolution of the system on the ${ }^{1}\left(\mathrm{~L}_{\mathrm{a}} \pi \pi^{*}\right),{ }^{1}\left(\mathrm{~L}_{\mathrm{b}} \pi \pi^{*}\right),{ }^{1}\left(\mathrm{n}_{\mathrm{B}} \pi^{*}\right),{ }^{1}\left(\mathrm{n}_{\mathrm{A}} \pi^{*}\right)$, ground state, ${ }^{3}\left(\pi_{\mathrm{O}} \pi^{*}\right)$, and ${ }^{3}\left(\mathrm{n}_{\mathrm{A}} \pi^{*}\right)$ respectively, obtained via the computed CASPT2// CASSCF minimum energy path and linear interpolation of internal coordinates.

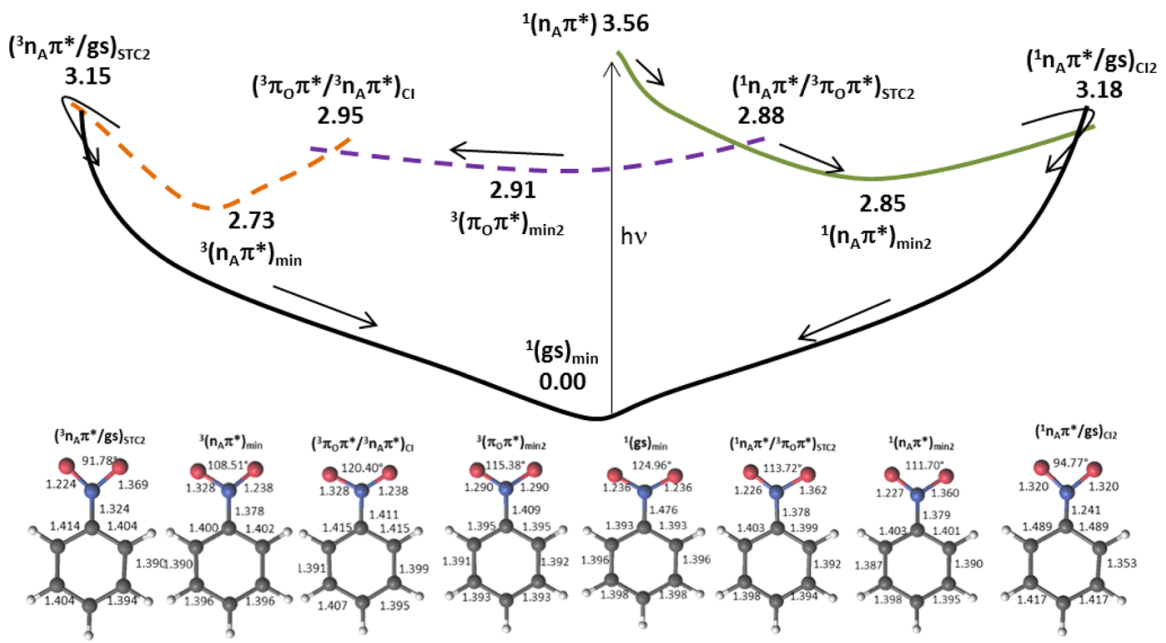

Figure 7. Schematic representation of the main decay paths that after excitation into the ${ }^{1}\left(\mathrm{n}_{\mathrm{A}} \pi^{*}\right)$ state evolve toward radiationless repopulation of the original ground state. Solid olive-green, solid black, dashed purple, and dashed orange lines indicate the evolution of the system on the ${ }^{1}\left(\mathrm{n}_{\mathrm{A}} \pi^{*}\right)$, ground state, ${ }^{3}\left(\pi_{\mathrm{O}} \pi^{*}\right)$, and ${ }^{3}\left(\mathrm{n}_{\mathrm{A}} \pi^{*}\right)$, respectively, obtained via the computed CASPT2//CASSCF minimum energy path and linear interpolation of internal coordinates. The geometries of the corresponding critical points are also depicted, reporting selected the bond lengths (in $\AA$ ) and angles (in deg).

from the ${ }^{1}(\mathrm{gs})_{\min }$ structure to the one above-described for the same state populated through the $\left({ }^{1} \mathrm{n}_{\mathrm{A}} \pi^{*} /{ }^{1} \mathrm{n}_{\mathrm{B}} \pi^{*}\right)_{\mathrm{CI}}$ conical intersection has been characterized (see Figure S6 and S7). The profiles reported in Figure $S 7$ show how the ${ }^{1}\left(\mathrm{n}_{\mathrm{A}} \pi^{*}\right)$ can decay to a minimum region, ${ }^{1}\left(\mathrm{n}_{\mathrm{A}} \pi^{*}\right)_{\min 2}$, from which the molecule can reach a CI with the ground state, $\left({ }^{1} n_{\mathrm{A}} \pi^{*} / \mathrm{gs}\right)_{\mathrm{CI} 2}$, surmounting an energy barrier of at most $0.33 \mathrm{eV}$, leading to the repopulation of the latter state.

Along the decay toward the ${ }^{1}\left(\mathrm{n}_{\mathrm{A}} \pi^{*}\right)_{\min 2}$ minimum, a STC region between the ${ }^{1}\left(\mathrm{n}_{\mathrm{A}} \pi^{*}\right)$ and the ${ }^{3}\left(\pi_{\mathrm{O}} \pi^{*}\right)$ states is encountered, $\left({ }^{1} n_{\mathrm{A}} \pi^{*} /{ }^{3} \pi_{\mathrm{O}} \pi^{*}\right)_{\mathrm{STC} 2}$, that due to its high SOC value $\left(68.31 \mathrm{~cm}^{-1}\right)$ is most likely the explanation for the high value of the triplet quantum yield (0.80) experimentally detected..$^{5}$ Once populated, the ${ }^{3}\left(\pi_{\mathrm{O}} \pi^{*}\right)$ state can decay from a minimum structure, ${ }^{3}\left(\pi_{\mathrm{O}} \pi^{*}\right)_{\min 2}$, to the lower ${ }^{3}\left(\mathrm{n}_{\mathrm{A}} \pi^{*}\right)$ state through the $\left({ }^{3} \pi_{\mathrm{O}} \pi^{*} /{ }^{3} \mathrm{n}_{\mathrm{A}} \pi^{*}\right)_{\mathrm{CI}}$. Finally the ${ }^{3}\left(\mathrm{n}_{\mathrm{A}} \pi^{*}\right)$ state can populate the ground state radiationlessly evolving from the ${ }^{3}\left(\mathrm{n}_{\mathrm{A}} \pi^{*}\right)_{\text {min }}$ minimum to a STC region $\left({ }^{3} \mathrm{n}_{\mathrm{A}} \pi^{*} / \mathrm{gs}\right)_{\mathrm{STC} 2}$, which is $0.42 \mathrm{eV}$ higher in energy, again characterized by an high SOC value, $74.97 \mathrm{~cm}^{-1}$. The latter energy barrier, $0.32 \mathrm{eV}$ higher than the one found between the ${ }^{3}\left(\mathrm{n}_{\mathrm{A}} \pi^{*}\right)_{\min }$ and the $\left({ }^{3} \mathrm{n}_{\mathrm{A}} \pi^{*} /\right.$ gs $)_{\text {STC }}$ structure, appears as the most significant feature differentiating the decay of the ${ }^{1}\left(\mathrm{n}_{\mathrm{A}} \pi^{*}\right)$ state from the ${ }^{1}(\mathrm{gs})_{\min }$ obtained averaging two roots and the decay from the $\left({ }^{1} \mathrm{n}_{\mathrm{A}} \pi^{*} /{ }^{1} \mathrm{n}_{\mathrm{B}} \pi^{*}\right)_{\mathrm{CI}}$ conical intersection obtained averaging six (five) singlet (triplet) roots.

The global paths here obtained after excitation into the ${ }^{1}\left(\mathrm{n}_{\mathrm{A}} \pi^{*}\right)$ state are schematically depicted in Figure 7.

Due to the significant difference between the CASSCF and CASPT2 optimized ground state geometries (see Figure S4), it is worth evaluating the influence of the level of optimization used in the excited states for the description of the photodecay path. In order to evaluate such a variable, the MEP on the ${ }^{1}\left(\mathrm{n}_{\mathrm{A}} \pi^{*}\right)$ state from the ${ }^{1}(\mathrm{gs})_{\min }$ minimum has been recomputed at the CASPT2 $(14,11)$ level. Comparing this with the MEP profile at the CASPT2//CASSCF level (see Figure S8), some important remarks are worth noticing. In both cases (i.e., CASSCF optimization and CASPT2 optimization), the system 
is distorted in a similar fashion, but at the final CASPT2 point, hereafter ${ }^{1}\left(\mathrm{n}_{\mathrm{A}} \pi^{*}\right)_{\text {min-caspt2, }}$, the two nitrogen-oxygen bonds are elongated by the same value, while the CASSCF optimization leads to different lengths for the $\mathrm{N}_{7} \mathrm{O}_{8}$ and $\mathrm{N}_{7} \mathrm{O}_{9}$ bonds. Second, an inversion of the energy order of the ${ }^{1}\left(\mathrm{n}_{\mathrm{A}} \pi^{*}\right)$ and ${ }^{3}\left(\pi_{\mathrm{O}} \pi^{*}\right)$ states is recorded in both cases; the ${ }^{1}\left(\mathrm{n}_{\mathrm{A}} \pi^{*}\right)$ state is higher in energy than the ${ }^{3}\left(\pi_{\mathrm{O}} \pi^{*}\right)$ state at the ${ }^{1}(\mathrm{gs})_{\min }$ structure, but the reverse ordering is computed at the final points of the two MEP profiles. An actual STC region along the CASPT2-MEP has not been found but can probably be obtained by reducing the sphere used in the MEP computation (see Methods section). At the ${ }^{1}\left(\mathrm{n}_{\mathrm{A}} \pi^{*}\right)_{\text {min-caspt2 }}$, the ${ }^{1}\left(\mathrm{n}_{\mathrm{A}} \pi^{*}\right)$ and ${ }^{3}\left(\pi_{\mathrm{O}} \pi^{*}\right)$ states are separated by $0.64 \mathrm{eV}$, while in the ${ }^{1}\left(\mathrm{n}_{\mathrm{A}} \pi^{*}\right)_{\min 2}$ minimum, a smaller energy gap of $0.16 \mathrm{eV}$ has been computed. The latter difference can play an important role in the decay process from the ${ }^{1}\left(\mathrm{n}_{\mathrm{A}} \pi^{*}\right)$ to the ${ }^{3}\left(\pi_{\mathrm{O}} \pi^{*}\right)$ state, whose efficiency can consequently change on the basis of CASPT2 or CASPT2//CASSCF PEHs.

Having characterized the main decay paths of the system, we can now make a comparison with previous theoretical studies on the system. The decay from the ${ }^{1}\left(\mathrm{n}_{\mathrm{A}} \pi^{*}\right)$ state and from the triplet to the ground state have been previously rationalized by Dreuw, Marian, and co-workers ${ }^{8}$ and by the work of Quenneville et al. ${ }^{40}$ Dreuw, Marian, and co-workers have found a conical intersection between ${ }^{1}\left(\mathrm{n}_{\mathrm{A}} \pi^{*}\right)$ and the ground state, $0.6 \mathrm{eV}$ above the ${ }^{1}\left(\mathrm{n}_{\mathrm{A}} \pi^{*}\right)$ minimum. The main deformation of this $\mathrm{CI}$ is the tighter ONO angle although, analyzing the provided data, a shortening of the carbonnitrogen bond is also present. The result is then in agreement with that obtained in the present study: from the ${ }^{1}\left(\mathrm{n}_{\mathrm{A}} \pi^{*}\right)$ equilibrium point, a $\mathrm{CI}$ with the ground state characterized by a shorter $\mathrm{CN}$ bond is reachable by surmounting an energy barrier of around $0.5 \mathrm{eV}$. The study performed by Quenneville et al. using the TDDFT method described a different CI involving an out of plane distortion of the nitro group. The latter geometry has been here recomputed at the CASPT2 $(14,11)$ level for the sake of comparison, and it has been found to be around $0.5 \mathrm{eV}$ higher in energy than the here characterized $\left({ }^{1} \mathrm{n}_{\mathrm{A}} \pi^{*} / \mathrm{gs}\right)_{\mathrm{CI}}$ and $\left({ }^{1} n_{\mathrm{A}} \pi^{*} / \mathrm{gs}\right)_{\mathrm{C} 2}$ structures, which suggests a smaller involvement of the out of plane distorted CI in the photophysics of the system.

Regarding the decay from the triplet manifold, Quenneville et al. suggested the involvement of the same out of plane structure as the one involved in the decay from the $S_{1}$ to the $S_{0}$, as this geometry is also a singlet-triplet crossing region with the ground state. Again, a higher CASPT2 $(14,11)$ energy of around $0.5 \mathrm{eV}$ has been computed for this point with respect to the $\left({ }^{3} n_{\mathrm{A}} \pi^{*} / \mathrm{gs}\right)_{\mathrm{STC}}$ and $\left({ }^{3} \mathrm{n}_{\mathrm{A}} \pi^{*} / \mathrm{gs}\right)_{\mathrm{STC} 2}$ points. Dreuw, Marian, and co-workers have described a STC region between the ${ }^{3}\left(\pi_{\mathrm{O}} \pi^{*}\right)$ and the ground state, characterized by a value of the dihedral angle ONCO equal to $120^{\circ}$, which is consequently a nonplanar structure. The structure has been computed at 3.1$3.0 \mathrm{eV}$ with respect to the ground state minimum, at a similar relative energy as the $\left({ }^{3} \mathrm{n}_{\mathrm{A}} \pi^{*} / \mathrm{gs}\right)_{\mathrm{STC} 2}$ here obtained, but at around $0.3 \mathrm{eV}$ above the $\left({ }^{3} \mathrm{n}_{\mathrm{A}} \pi^{*} / \mathrm{gs}\right)_{\mathrm{STC}}$ structure.

Two main differences are thus observed with respect to the present results. First, the here computed STC with the ground state involved the ${ }^{3}\left(\mathrm{n}_{\mathrm{A}} \pi^{*}\right)$ state and not the ${ }^{3}\left(\pi_{\mathrm{O}} \pi^{*}\right)$ state. Second, the $\left({ }^{3} n_{\mathrm{A}} \pi^{*} / \mathrm{gs}\right)_{\mathrm{STC}}$ and $\left({ }^{3} \mathrm{n}_{\mathrm{A}} \pi^{*} / \mathrm{gs}\right)_{\mathrm{STC}}$ regions are planar structures while the STC characterized by Dreuw, Marian, and co-workers, being characterized by a dihedral angle $\mathrm{ONCO}$ of $120^{\circ}$, is not planar. The latter geometrical feature allows a sizable coupling between the ${ }^{3}\left(\pi_{\mathrm{O}} \pi^{*}\right)$ and the ground state, which is otherwise characterized by a small SOC value for planar geometries. For the sake of comparison the SOC between the ${ }^{3}\left(\pi_{\mathrm{O}} \pi^{*}\right)$ and the ground state at their STC structure have been here computed, and the value of 57.01 $\mathrm{cm}^{-1}$ has been obtained, which is significantly high but smaller than the SOC at the $\left({ }^{3} n_{\mathrm{A}} \pi^{*} / \mathrm{gs}\right)_{\text {STC }}$ and $\left({ }^{3} \mathrm{n}_{\mathrm{A}} \pi^{*} / \mathrm{gs}\right)_{\text {STC2 }}$ geometries, which is on the order of $70 \mathrm{~cm}^{-1}$.

Finally, an attempt to rationalize the three experimentally recorded lifetimes (100 fs, $6 \mathrm{ps}$, and $480 \mathrm{ps)}$ can be made on the basis of the characterized PEHs.

A first explanation is that the decay from the ${ }^{1}\left(\mathrm{n}_{\mathrm{A}} \pi^{*}\right)$ back to the original ground state through the $\left({ }^{1} n_{\mathrm{A}} \pi^{*} / \mathrm{gs}\right)_{\mathrm{CI} 2}$ is responsible for the $100 \mathrm{fs}$ lifetime, the 6 ps decay reflects the passage from the singlet to the triplet manifold mediated by the $\left({ }^{1} n_{\mathrm{A}} \pi^{*} /{ }^{3} \pi_{\mathrm{O}} \pi^{*}\right)_{\mathrm{STC} 2}$, and the $480 \mathrm{ps}$ lifetime corresponds to the relaxation from the ${ }^{3}\left(\mathrm{n}_{\mathrm{A}} \pi^{*}\right)$ to the ground state by means of the $\left({ }^{3} n_{\mathrm{A}} \pi^{*} / \mathrm{gs}\right)_{\mathrm{STC} 2}$. According to this scenario, after excitation into the ${ }^{1}\left(\mathrm{n}_{\mathrm{A}} \pi^{*}\right)$ state, the system is able to surmount the $0.33 \mathrm{eV}$ energy barrier separating the ${ }^{1}\left(\mathrm{n}_{\mathrm{A}} \pi^{*}\right)$ and $\left({ }^{1} \mathrm{n}_{\mathrm{A}} \pi^{*} / \mathrm{gs}\right)_{\mathrm{CI} 2}$ structures in an ultrafast process, and the presence of the accessible and presumably efficient $\left({ }^{1} n_{\mathrm{A}} \pi^{*} /{ }^{3} \pi_{\mathrm{O}} \pi^{*}\right)_{\text {STC2 }}$ STC determines a fast decay from the singlet to the triplet manifold. Thus, the ultrafast $S_{1}$ to $S_{0}$ decay appears plausible evolving from the FC region toward first the ${ }^{1}\left(\mathrm{n}_{\mathrm{A}} \pi^{*}\right)_{\min }$ minimum and then the $\left({ }^{1} n_{\mathrm{A}} \pi^{*} / \mathrm{gs}\right)_{\mathrm{CI} 2} \mathrm{CI}$ as the molecule is distorted along the same main coordinates (i.e., shortening of the carbon-nitrogen bond and decrease of the ONO angle). However, similar energy barriers connecting the $S_{1}$ minimum to an $S_{1} / S_{0}$ CI have been proposed to be responsible for longer lifetimes in the picosecond regime for other systems. ${ }^{28,41}$

A second explanation can be formulated on the basis of the known photophysical properties of another nitroaromatic molecule. 1-Nitronaphthalene is the organic compound with the fastest multiplicity change ever measured (around 100 fs) ${ }^{42,43}$ This property has been explained by the fact that the $\mathrm{PEH}$ along the MEP profile from the FC region of the excited singlet state, which has the same nature as the here described ${ }^{1}\left(\mathrm{n}_{\mathrm{A}} \pi^{*}\right)$ state, is strongly coupled with the $\mathrm{PEH}$ of a triplet state. This is characterized by the same main configuration describing the ${ }^{3}\left(\pi_{\mathrm{O}} \pi^{*}\right)$ state, is energetically close (around 0.15 $\mathrm{eV}$ energy gap), and displays a SOC value of the order of 70 $\mathrm{cm}^{-1} \cdot{ }^{16,24}$ These features are the same as those describing the ${ }^{1}\left(\mathrm{n}_{\mathrm{A}} \pi^{*}\right)$ and ${ }^{3}\left(\pi_{\mathrm{O}} \pi^{*}\right)$ states in NB along the ${ }^{1}\left(\mathrm{n}_{\mathrm{A}} \pi^{*}\right)$ MEP from the ${ }^{1}(\mathrm{gs})_{\min }$ structure. Since the experimental data on NB and 1-nitronaphthalene are recorded in solution (ethanol and methanol, respectively) the interaction with the surrounding environment may lead to different effects on the two molecules. An alternative explanation is that also in NB an ultrafast decay from the singlet to the triplet states takes place and that consequently the three lifetimes can be explained as follow: the $100 \mathrm{fs}$ is due to the decay into the ${ }^{3}\left(\pi_{\mathrm{O}} \pi^{*}\right)$ state, the 6 ps process accounts for the relaxation through the $\left({ }^{1} n_{\mathrm{A}} \pi^{*} / \mathrm{gs}\right)_{\mathrm{CI} 2}$ $\mathrm{CI}$, and again the $480 \mathrm{ps}$ is associated with the population of the ground state at the $\left({ }^{3} n_{\mathrm{A}} \pi^{*} / \mathrm{gs}\right)_{\mathrm{STC} 2}$ STC.

In order to clearly assign the experimentally recorded lifetimes to different photoinduced processes, quantum dynamics simulations are required. Such a study, which goes beyond the purpose of the present work, will be presented in a later contribution. ${ }^{44}$

Photodegradation. So far we have focused on the radiationless processes that bring back NB to the original ground state minimum after excitation. In the present section, 

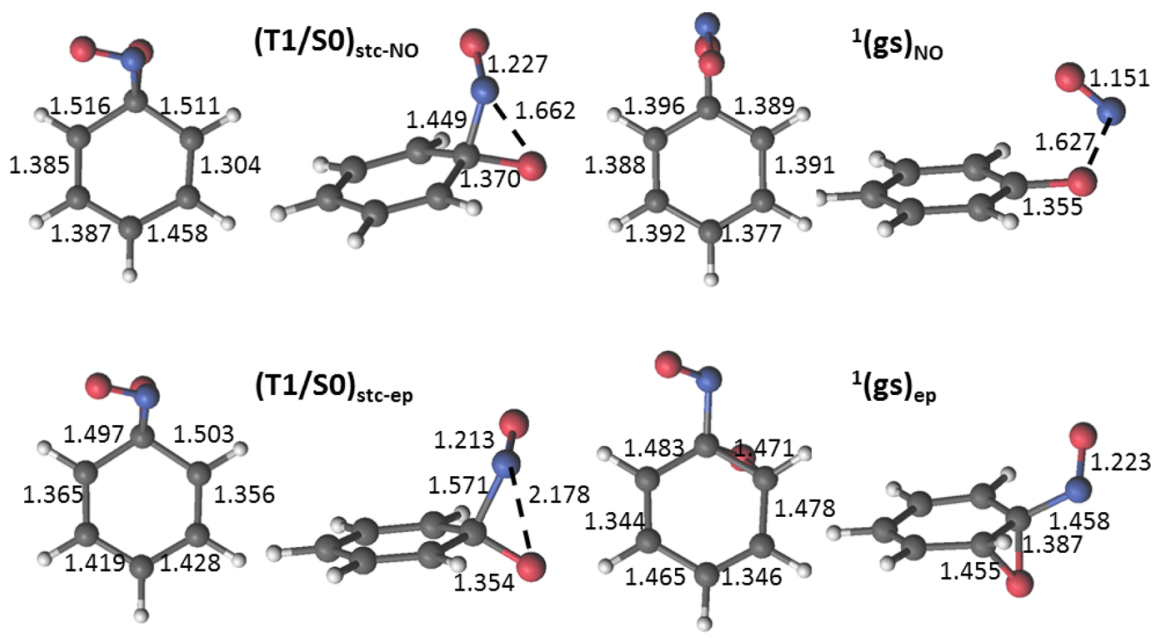

Figure 8. Main geometries involved in the two photodegradation paths summarized in Figure 9. Bond lengths are reported in Å.

the possibility of photoinduced reactive paths responsible for the known photochemistry of the system are discussed.

Nitrated polycyclic aromatic hydrocarbons are known to photodegrade into nitrogen(II) oxide plus the corresponding aryloxy radical through a first photoactivated step leading to the photoisomerization of the nitro into a nitrite group, followed by a second thermally activated step breaking the system into the two radicals. ${ }^{45-47}$ Two mechanisms have been proposed in order to explain the photoisomerization: the so-called dissociation-recombination mechanism, characterized by the cleavage of the $\mathrm{CN}$ bond, and the intramolecular rearrangement mechanism, involving the formation of an oxaziridine ring. ${ }^{45}$ The latter mechanism has been theoretically documented for 1nitronaphthalene to occur through the presence of an accessible STC between the triplet and the ground state, where the oxaziridine ring is formed. ${ }^{16}$ Due to the chemical similarity between NB and 1-nitronaphthalene, it is interesting to evaluate if a similar mechanism may play a role in the photodegradation on $\mathrm{NB}$, as also suggested in previous works. $10,11,13$

Since the photochemistry of NB will lead to the breaking of covalent bonds (such as the $\mathrm{CN}$ bond in order to form $\mathrm{NO}_{2}$ ) in the following computations the $(14,11)$ active space has been enlarged to $(16,13)$ to include the pair of bonding and antibonding $\sigma$ orbitals describing the breaking bond. All the following energies are then referred to the ${ }^{1}(\mathrm{gs})_{\min }$ minimum, recomputed at the CASPT2 $(16,13)$ level. A state-averaged scheme over two singlet and two triplet states have been used in the present section.

Two STC regions between the S0 and T1 states have been found displaying an oxaziridine-like geometry, hereafter named as $(\mathrm{T} 1 / \mathrm{S} 0)_{\text {stc-NO }}$ and $(\mathrm{T} 1 / \mathrm{S} 0)_{\text {stc-ep }}$, placed at 3.83 and $3.39 \mathrm{eV}$ with respect to the ${ }^{1}(\mathrm{gs})_{\min }$ minimum and characterized by a SOC value of 4.11 and $4.69 \mathrm{~cm}^{-1}$, respectively (see Figure 8). In such geometries, the triplet state crossing the ground state is most likely the ${ }^{3}\left(\pi_{\mathrm{O}} \pi^{*}\right)$ state, although the structural deformation of the system prevents a clear identification of the electronic states.

In order to evaluate the importance of $(\mathrm{T} 1 / \mathrm{S} 0)_{\text {stc-NO }}$ and $(\mathrm{T} 1 / \mathrm{S} 0)_{\text {stc-ep }}$ in the NB photochemistry, the PEHs between the ${ }^{3}\left(\pi_{\mathrm{O}} \pi^{*}\right)_{\min }$ minimum and these STC regions have been explored, and MEPs on the ground state have been calculated from the crossing points.
A path connecting the ${ }^{3}\left(\pi_{\mathrm{O}} \pi^{*}\right)_{\min }$ and the $(\mathrm{T} 1 / \mathrm{S} 0)_{\text {stc-NO }}$ structures has been obtained performing a LIIC computation between the ${ }^{3}\left(\pi_{\mathrm{O}} \pi^{*}\right)_{\min }$ and a geometry obtained reducing the $\mathrm{C}_{3} \mathrm{C}_{2} \mathrm{C}_{1} \mathrm{~N}_{7}$ dihedral angle of the $(\mathrm{T} 1 / \mathrm{S} 0)_{\text {stc-No }}$ point from the value of $-111.69^{\circ}$ to $-130.00^{\circ}$, while keeping all other geometrical parameters fixed. The so obtained structure can be considered connected to the $(\mathrm{T} 1 / \mathrm{S} 0)_{\text {stc-NO}}$, and in fact the T1 state energy changes by only $0.13 \mathrm{eV}$ (see Table S4). Such a procedure has been done since a LIIC between the ${ }^{3}\left(\pi_{\mathrm{O}} \pi^{*}\right)_{\min }$ and the $(\mathrm{T} 1 / \mathrm{S} 0)_{\text {stc-NO }}$ structures results in geometries in which one oxygen atom is not bonded to any other atoms. The PEHs of the S0 and T1 along the described path are reported in Figure S10. On the basis of the computed energies along the path (see Table S4), the system has to surmount a significant energy barrier of $1.32 \mathrm{eV}$ in order to evolve toward the (T1/ S0) $)_{\text {stc-NO }}$ structure from the ${ }^{3}\left(\pi_{\mathrm{O}} \pi^{*}\right)_{\min }$ minimum.

From the $(\mathrm{T} 1 / \mathrm{S} 0)_{\text {stc-NO }} \mathrm{STC}$, the ground state can release $\mathrm{NO}$, as proven by the computation of the corresponding MEP (see Figure S11), which evolves toward a minimum, hereafter ${ }^{1}(\mathrm{gs})_{\mathrm{NO}}$, where the NO molecule and the corresponding phenoxy radical have been formed. In the latter structure, the NO bond length is equal to $1.151 \AA$, which is indeed the value characterizing the NO molecule, while the distance between the nitrogen atom and the oxygen atom of the phenoxy radical is equal to $1.627 \AA$ (see Figure 8).

A path connecting the ${ }^{3}\left(\pi_{\mathrm{O}} \pi^{*}\right)_{\min }$ and the $(\mathrm{T} 1 / \mathrm{S} 0)_{\text {stc-NO }}$ structures has also been obtained. Due to the large geometrical deformation experienced by the molecule from the former to the latter geometry, a LIIC between then produces unlikely structures. For that reason, the path has been obtained computing a LIIC between the ${ }^{3}\left(\pi_{\mathrm{O}} \pi^{*}\right)_{\min }$ structure in which the nitro group has been placed out of the plane of the ring, setting the $\mathrm{C}_{2} \mathrm{C}_{1} \mathrm{~N}_{7} \mathrm{O}_{9}$ dihedral angle to $45^{\circ}$, and a geometry obtained reducing the $\mathrm{C}_{3} \mathrm{C}_{2} \mathrm{C}_{1} \mathrm{~N}_{7}$ dihedral angle of the (T1/ S0) $)_{\text {stc-ep }}$ point from the value of $-116.74^{\circ}$ to $-150.00^{\circ}$, while keeping all other geometrical parameters fixed. Along the resultant path (see Figure S10 and Table S5), an energy barrier of $1.12 \mathrm{eV}$ has been computed. From the crossing, a MEP on the ground state has been performed as displayed in Figure S11. The ground state evolves to a minimum structure, hereafter ${ }^{1}(\mathrm{gs})_{\mathrm{ep}}$, characterized by the formation of an epoxide ring involving the $\mathrm{C}_{2} \mathrm{C}_{1} \mathrm{O}_{9}$ atoms. The geometry has been confirmed to be a minimum through the computation of the 
a)

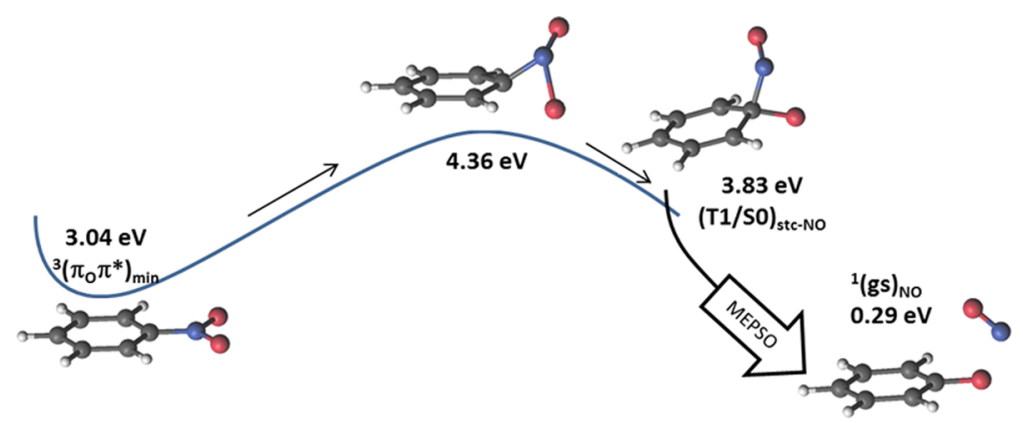

b)

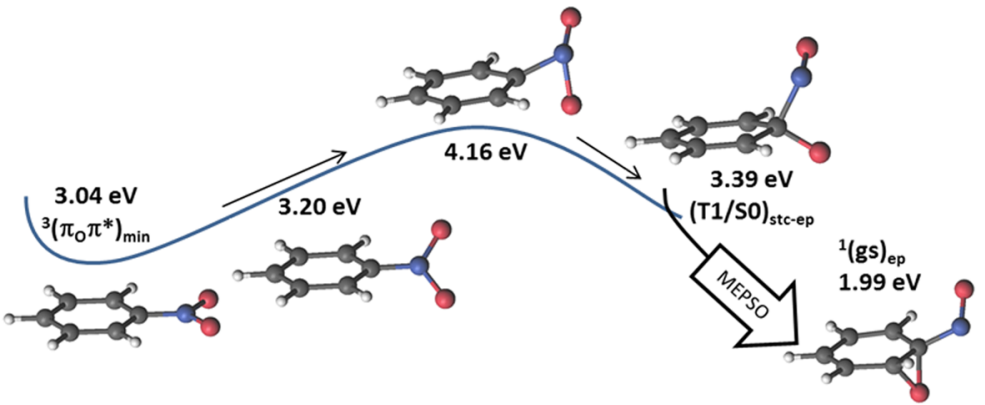

Figure 9. (a) Photodegradation path from the ${ }^{3}\left(\pi_{\mathrm{O}} \pi^{*}\right)_{\min }$ minimum toward the $(\mathrm{T} 1 / \mathrm{S} 0)_{\text {stc-NO }}$ STC and finally leading to the ${ }^{1}$ (gs) $)_{\mathrm{NO}}$ structure. $(\mathrm{b})$ Photodegradation path from the ${ }^{3}\left(\pi_{\mathrm{O}} \pi^{*}\right)_{\min }$ minimum toward the $(\mathrm{T} 1 / \mathrm{S} 0)_{\text {stc-ep }}$ STC and finally leading to the ${ }^{1}(\mathrm{gs})_{\mathrm{ep}}$ structure. CASSCF $(16,13)$ energies (in $\mathrm{eV}$ ) are also reported.

corresponding CASSCF frequencies. The ${ }^{1}(\mathrm{gs})_{\mathrm{ep}}$ structure is placed $1.99 \mathrm{eV}$ above the ${ }^{1}(\mathrm{gs})_{\min }$ minimum.

Figures 8 and 9 summarize the main results of the abovedescribed photochemical paths. In both cases, the system has to surmount a point placed more than $4.00 \mathrm{eV}$ above the ground state minimum, although the obtained barriers are upper bounds of the actual barriers characterizing the processes. This is in line with the fact that experimentally the $\mathrm{NB}^{\prime}$ photoreaction products have been observed after excitation higher than $3.87 \mathrm{eV}(320 \mathrm{~nm}) .^{9}$ In Tables S4 and S5 of the SI the energies along the computed paths are reported, while in Figure S9 the active space at the characterized STCs is depicted.

On the basis of the obtained results, it appears that from the NB triplet manifold the system is able to decay toward photodegradation products without needing to photoisomerize the nitro into the nitrite group. Nevertheless, the formation of $\mathrm{NO}$ and the corresponding phenoxy radical or the nitro-nitrite photoisomerization is probably significantly sensitive to small geometrical deformations of the STC point from which the ground state is repopulated, and so the possibility of a nitronitrite photoisomerization mediated by a oxaziridine-like STC region is not here excluded.

The photoisomerization process of the nitro into the nitrite group has also been proposed take place according to a different mechanism not involving an oxaziridine-like STC structure. Suits and co-workers have proposed the involvement of a roaming mechanism taking place on the ground state after relaxation from the excited manifold, characterized by the frustrated dissociation of nitro group, which will subsequently rebond the benzene ring forming a new oxygen-carbon bond, leading to the nitrite isomer. ${ }^{13}$ Such a possibility has made us wonder about a possible implication of the $\left({ }^{1} n_{\mathrm{A}} \pi^{*} / \mathrm{gs}\right)_{\mathrm{Cl} 2}$ and $\left({ }^{3} n_{\mathrm{A}} \pi^{*} / \mathrm{gs}\right)_{\mathrm{STC} 2}$ in the photochemistry of the system. Both critical points are characterized by a significant shortening of the $\mathrm{CN}$ bond with respect to the ${ }^{1}(\mathrm{gs})_{\min }$ structure $(0.235$ and $0.152 \AA$, respectively). From such degenerate points, the system on the ground state PEHs decaying toward the ${ }^{1}(\mathrm{gs})_{\min }$ structure is then evolving along the stretching coordinate of the $\mathrm{CN}$ bond. It will then be interesting to evaluate if the energy gained along such decay paths will be sufficient to keep the molecule evolving along the same stretching coordinate to $\mathrm{CN}$ bond breaking and consequently to be responsible for the frustrated dissociation of the nitro group proposed by Suits and co-workers.

In the present study, this possibility has been evaluated by computing the energy of the molecule while systematically elongating the carbon-nitrogen bond of the ground state minimum structure. Since the process leads to the breaking of the $\mathrm{C}_{1} \mathrm{~N}_{7}$ bond, in order to correctly compute, the corresponding energies the $(14,11)$ active space have been again expanded to include the $\sigma, \sigma^{*}$ orbitals localized on the $\mathrm{C}_{1} \mathrm{~N}_{7}$ bond (see Figure S12). The energies of the ground state at different $\mathrm{C}_{1} \mathrm{~N}_{7}$ bond lengths are reported in Table 3. At a distance between the $C_{1}$ and $N_{7}$ atoms of $3.00 \AA$, a structure in which the nitro group can then be considered completely

Table 3. CASPT2//CASSCF $(16,13)$ Energy of the Ground State at Different $\mathrm{C}_{1} \mathrm{~N}_{7}$ Bond Distance, Keeping all Other Bond Lengths as in the ${ }^{1}(\mathrm{gs})_{\min }$ Structure

$\begin{array}{lr}\mathrm{C}_{1} \mathrm{~N}_{7} \text { distance }(\AA) & \text { ground state energy }^{a}(\mathrm{eV}) \\ 1.476\left[{ }^{1}(\mathrm{gs})_{\mathrm{min}}\right] & 0.00 \\ 1.500 & 0.04 \\ 1.600 & 0.17 \\ 1.700 & 0.44 \\ 1.800 & 0.75 \\ 1.900 & 1.07 \\ 2.000 & 1.36 \\ 3.000 & 2.92\end{array}$

${ }^{a}$ All the reported values are referred to the ground state optimized geometry, ${ }^{1}(\mathrm{gs})_{\min }$, computing its energy at the CASPT2//CASSCF$(16,13)$ level 
detached from the aromatic ring and in the range of distances at which roaming reactions are believed to take place $(3-4 \AA),{ }^{13}$ the ground state energy has increased by $2.92 \mathrm{eV}$ with respect to the ${ }^{1}(\mathrm{gs})_{\min }$ geometry. The involvement of the $\left({ }^{1} n_{\mathrm{A}} \pi^{*} / \mathrm{gs}\right)_{\mathrm{CI} 2}$ and $\left({ }^{3} n_{\mathrm{A}} \pi^{*} / \mathrm{gs}\right)_{\mathrm{STC} 2}$ critical points in the system's photochemistry is currently under investigation using quantum dynamics simulations.

\section{CONCLUSIONS}

In the present contribution, the photophysics of nitrobenzene after UV absorption have been studied using the CASPT2// CASSCF approach from both the brightest ${ }^{1}\left(\mathrm{~L}_{\mathrm{a}} \pi \pi^{*}\right)$ state and the ${ }^{1}\left(\mathrm{n}_{\mathrm{A}} \pi^{*}\right)$ state.

On the basis of the obtained results, different photophysical properties experimentally recorded for the system have been rationalized: the lack of fluorescence and phosphorescence emission is attributable to the presence of accessible CI and STC regions involving, respectively, the ${ }^{1}\left(\mathrm{n}_{\mathrm{A}} \pi^{*}\right) \mathrm{S}_{1}$ and ${ }^{3}\left(\mathrm{n}_{\mathrm{A}} \pi^{*}\right) \mathrm{T}_{1}$ state with the ground state; the high value of the triplet quantum yield is in agreement with the obtained strong coupling between the ${ }^{1}\left(\mathrm{n}_{\mathrm{A}} \pi^{*}\right)$ and ${ }^{3}\left(\pi_{\mathrm{O}} \pi^{*}\right)$ PEHs; two possible explanations of the three recorded lifetimes have been formulated, whose plausibility must be tested by performing dynamics simulations.

The presented results partially agree with conclusions draw by Dreuw, Marian, and co-workers: ${ }^{8}$ while the decay from the ${ }^{1}\left(\mathrm{n}_{\mathrm{A}} \pi^{*}\right)$ to the ground state and the explanation of the high triplet quantum yield nicely match, the structure and states involved in the relaxation from the triplet manifold back to the original ground state differ significantly.

The rich photochemistry of the title molecule has been also investigated. Two not previously reported STC regions between the ${ }^{3}\left(\pi_{\mathrm{O}} \pi^{*}\right)$ and the ground state have been characterized. From the latter geometries, in which the nitro group is distorted to form an oxaziridine-like ring structure, the ground state evolves toward the formation of $\mathrm{NO}$ and the corresponding phenoxy radical and toward the production of an epoxide ring structure, respectively. Another photodegradation mechanism in line with the roaming reaction presented in the experimental work of Suits and co-workers ${ }^{13}$ has been hypothesized. Its plausibility, together with the efficiency of the characterized decay paths, are currently under analysis in our group.

\section{ASSOCIATED CONTENT}

\section{S Supporting Information}

The Supporting Information is available free of charge on the ACS Publications website at DOI: 10.1021/acs.jctc.6b01149.

Active orbitals, main orbitals involved in the computed singlet excited states, main orbitals involved in the computed triplet excited states, nitrobenzene ground state structures optimized at different levels of theory and experimentally obtained from electron diffraction experiments, CASPT2 $(14,11)$ ground state optimized structures, comparison of the calculated vertical excitation energies for the computed singlet and triplet states, computed energies $(\mathrm{eV})$ for the most relevant singlet and triplet states of nitrobenzene at different critical points, minima, conical intersections, and singlet-triplet crossing regions characterized along the main decay path of the ${ }^{1}\left(\mathrm{n}_{\mathrm{A}} \pi^{*}\right)$ state, potential energy hypersurfaces of the most photophysically and photochemically relevant electronic states along the main decay path after excitation into the ${ }^{1}\left(\mathrm{n}_{\mathrm{A}} \pi^{*}\right)$ state at the ${ }^{1}(\mathrm{gs})_{\min }$ geometry, minimum energy path from the ${ }^{1}(\mathrm{gs})_{\min }$ structure on the ${ }^{1}\left(\mathrm{n}_{\mathrm{A}} \pi^{*}\right)$ state, CASPT2 $(16,13)$ computed energies $(\mathrm{eV})$ for the most relevant singlet and triplet states of nitrobenzene along the characterized paths, active space at the $(\mathrm{T} 1 / \mathrm{S} 0)_{\text {STC-NO }}$ and $(\mathrm{T} 1 / \mathrm{S} 0)_{\text {STC-ep }}$ reactive singlet-triplet crossing regions, paths between the $\left({ }^{3} \pi_{\mathrm{O}} \pi^{*}\right)_{\min }$ and the $(\mathrm{S} 0 / \mathrm{T} 1)_{\text {stc-NO }}$ structures and between the $\left({ }^{3} \pi_{\mathrm{O}} \pi^{*}\right)_{\min }$ and the $(\mathrm{S} 0 / \mathrm{T} 1)_{\text {stc-ep }}$ structures, MEP on the ground state from the $(\mathrm{SO} / \mathrm{T} 1)_{\text {stc-NO }}$ structure and from the $(\mathrm{S} 0 / \mathrm{T} 1)_{\text {stc-ep }}$ structure, active space used for the CASPT2 $(16,13)$ computation of the ${ }^{1}(\mathrm{gs})_{\text {min }}$ geometry in which the $\mathrm{CN}$ bond has been elongated to the value of $3 \AA$, reference weights of the different CASSCF states in the corresponding CASPT2 computation, and Cartesian coordinates $x, y, z$ (in $\AA$ ) of the optimized structures for the nitrobenzene molecule (PDF)

\section{AUTHOR INFORMATION}

\section{Corresponding Author}

*E-mail: angelo.giussani@ucl.ac.uk.

ORCID

Angelo Giussani: 0000-0002-9452-7641

Notes

The authors declare no competing financial interest.

\section{ACKNOWLEDGMENTS}

This project has received funding from the European Union's Horizon 2020 research and innovation programme under the Marie Sklodowska-Curie Grant Agreement No. 658173.

\section{REFERENCES}

(1) Atkinson, R.; Tuazon, E. C.; Wallington, T. J.; Aschmann, S. M.; Arey, J.; Winer, A. M.; Pitts, J. N. Atmospheric Chemistry of Aniline, N,N-dimethylaniline, Pyridine, 1,3,5-Triazine, and Nitrobenzene. Environ. Sci. Technol. 1987, 21, 64.

(2) Brill, T. B.; James, K. J. Kinetics and Mechanisms of Thermal Decomposition of Nitroaromatic explosives. Chem. Rev. 1993, 93, 2667.

(3) Nagakura, S.; Kojima, M.; Maruyama, Y. Electronic Spectra and Electronic Structures of Nitrobenzene and Nitromesitylene. J. Mol. Spectrosc. 1964, 13, 174.

(4) Vidal, B.; Murrell, J. N. The effect of Solvent on the Position of the First Absorption Band of Nitrobenzene. Chem. Phys. Lett. 1975, 31, 46.

(5) Takezaki, M.; Hirota, N.; Terazima, M. Nonradiative Relaxation Processes and Electronically Excited States of Nitrobenzene Studied by Picosecond Time-Resolved Transient Grating Method. J. Phys. Chem. A 1997, 101, 3443.

(6) Hurley, R.; Testa, A. C. Triplet-State Yield of Aromatic Nitro Compounds. J. Am. Chem. Soc. 1968, 90, 1949.

(7) Takezaki, M.; Hirota, N.; Terazima, M. Relaxation of Nitrobenzene from the Excited Singlet State. J. Chem. Phys. 1998, 108, 4685.

(8) Mewes, J.-M.; Jovanović, V.; Marian, C. M.; Dreuw, A. On the Molecular Mechanism of Non-Radiative Decay of Nitrobenzene and the Unforeseen Challenges this Simple Molecule Holds for Electronic Structure Theory. Phys. Chem. Chem. Phys. 2014, 16, 12393.

(9) Galloway, D. B.; Bartz, J. A.; Huey, L. G.; Crim, F. F. Pathways and Kinetic Energy Disposal in the Photodissociation of Nitrobenzene. J. Chem. Phys. 1993, 98, 2107.

(10) Lin, M.-F.; Lee, Y. T.; Ni, C.-K.; Xu, S.; Lin, M. C. Photodissociation Dynamics of Nitrobenzene and o-Nitrotoluene. J. Chem. Phys. 2007, 126, 064310. 
(11) He, Y.; Gahlmann, A.; Feenstra, J. S.; Park, S. T.; Zewail, A. H. Ultrafast Electron Diffraction: Structural Dynamics of Molecular Rearrangement in the NO Release from Nitrobenzene. Chem. - Asian J. 2006, $1,56$.

(12) Galloway, D. B.; Glenewinkel-Meyer, T.; Bartz, J. A.; Huey, L. G.; Crim, F. F. The Kinetic and Internal Energy of NO from the Photodissociation of Nitrobenzene. J. Chem. Phys. 1994, 100, 1946.

(13) Hause, M. L.; Herath, N.; Zhu, R.; Lin, M. C.; Suits, A. G. Roaming-Mediated Isomerization in the Photodissociation of Nitrobenzene. Nat. Chem. 2011, 3, 932.

(14) Jordan, M. J. T.; Kable, S. H. Roaming Reaction Pathways Along Excited States. Science 2012, 335, 1054.

(15) Bowman, J. M. Roaming. Mol. Phys. 2014, 112, 2516.

(16) Giussani, A. Toward the Understanding of the Photophysics and Photochemistry of 1-Nitronaphthalene under Solar Radiation: The First Theoretical Evidence of a Photodegradation Intramolecular Rearrangement Mechanism Involving the Triplet States. J. Chem. Theory Comput. 2014, 10, 3987.

(17) Giussani, A.; Segarra-Martí, J.; Roca-Sanjuán, D.; Merchán, M. Excitation of Nucleobases from a Computational Perspective I: Reaction Paths; Topics in Current Chemistry. Top. Curr. Chem. 2013, 355, 57.

(18) Andersson, K.; Malmqvist, P.-Å.; Roos, B. O. Second-Order Perturbation Theory with a Complete Active Space Self-Consistent Field Reference Function. J. Chem. Phys. 1992, 96, 1218.

(19) Roos, B. O.; Andersson, K.; Fülscher, M. P.; Malmqvist, P.-Å.; Serrano-Andrés, L.; Pierloot, K.; Merchán, M. Multiconfigurational Perturbation Theory: Applications in Electronic Spectroscopy. Adv. Chem. Phys. 1996, 93, 219.

(20) Serrano-Andrés, L.; Merchán, M. Spectroscopy: Applications. In Encyclopedia of Computational Chemistry, Schleyer, P. v. R., Schreiner, P. R, Schaefer, H. F., III, Jorgensen, W. L., Thiel, W., Glen, R. C., Eds.; Wiley: Chichester, 2004; pp 1-51.

(21) Aquilante, F.; Autschbach, J.; Carlson, R.; Chibotaru, L.; Delcey, M. G.; De Vico, L.; Fernández Galvan, I.; Ferré, N.; Frutos, L. M.; Gagliardi, L.; Garavelli, M.; Giussani, A.; Hoyer, C.; Li Manni, G.; Lischka, H.; Ma, D.; Malmqvist, P. A.; Müller, T.; Nenov, A.; Olivucci, M.; Pedersen, T. B.; Peng, D.; Plasser, F.; Pritchard, B.; Reiher, M.; Rivalta, I.; Schapiro, I.; Segarra-Martí, J.; Stenrup, M.; Truhlar, D. G.; Ungur, L.; Valentini, A.; Vancoillie, S.; Veryazov, V.; Vysotskiy, V.; Weingart, O.; Zapata, F.; Lindh, R. MOLCAS 8: New Capabilities for Multiconfigurational Quantum Chemical Calculations across the Periodic Table. J. Comput. Chem. 2016, 37, 506.

(22) Widmark, P.-O.; Malmqvist, P.-Å.; Roos, B. O. Density Matrix Averaged Atomic Natural Orbital (ANO) Basis Sets for Correlated Molecular Wave Functions. Theor. Chem. Acc. 1990, 77, 291.

(23) Pierloot, K.; Dumez, B.; Widmark, P.-O.; Roos, B. O. Density Matrix Averaged Atomic Natural Orbital (ANO) Basis Sets for Correlated Molecular Wave Functions. Theor. Chim. Acta 1995, 90, 87.

(24) Orozco-Gonzalez, Y.; Coutinho, K.; Peon, J.; Canuto, S. Theoretical Study of the Absorption and Nonradiative Deactivation of 1-Nitronaphthalene in the Low-Lying Singlet and Triplet Excited States Including Methanol and Ethanol Solvent Effects. J. Chem. Phys. 2012, 137, 054307.

(25) González-Luque, R.; Climent, T.; González-Ramírez, I.; Merchán, M.; Serrano-Andrés, L. Singlet-Triplet States Interaction Regions in DNA/RNA Nucleobase Hypersurfaces. J. Chem. Theory Comput. 2010, 6, 2103.

(26) Merchán, M.; Serrano-Andrés, L. Ab Initio Method for Excited States. In Computational Photochemistry, 1st ed.; Olivucci, M., Ed.; Elsevier: Amsterdam, 2005; Vol. 16, pp 35-91.

(27) Serrano-Andrés, L.; Merchán, M. Photostability and Photoreactivity in Biomolecules: Quantum Chemistry of Nucleic Acid Base Monomers and Dimers. In Radiation Induced Molecular Phenomena in Nucleic Acids, Leszczynski, J., Shukla, M., Eds.; Springer: The Netherlands, 2008; pp 435-472.

(28) Montero, R.; Longarte, A.; Conde, Á. P.; Redondo, C.; Castaño, F.; Gonzalez-Ramírez, I.; Giussani, A.; Serrano-Andrés, L.; Merchán,
M. Photophysics of 1-Aminonaphthalene: A Theoretical and TimeResolved Experimental Study. J. Phys. Chem. A 2009, 113, 13509.

(29) Giussani, A.; Pou-Amérigo, R.; Serrano-Andrés, L.; FreireCorbacho, A.; Martínez-García, C.; Fernández P., M. A.; Sarakha, M.; Canle L., M.; Santaballa, J. A. Combined Theoretical and Experimental Study of the Photophysics of Asulam. J. Phys. Chem. A 2013, 117, 2125.

(30) De Vico, L.; Olivucci, M.; Lindh, R. New General Tools for Constrained Geometry Optimizations. J. Chem. Theory Comput. 2005, 1, 1029.

(31) Anglada, J. M.; Bofill, J. M. A Reduced-Restricted- QuasiNewton Raphson Method for Locating and Optimizing Energy Crossing Points Between Two Potential Energy Surfaces. J. Comput. Chem. 1997, 18, 992.

(32) Garavelli, M. Computational Organic Photochemistry: Strategy, Achievements and Perspectives. Theor. Chem. Acc. 2006, 116, 87.

(33) Giussani, A.; Serrano-Andrés, L.; Merchán, M.; Roca-Sanjuán, D.; Garavelli, M. Photoinduced Formation Mechanism of the Thymine-Thymine (6-4) Adduct. J. Phys. Chem. B 2013, 117, 1999.

(34) Giussani, A.; Merchán, M.; Gobbo, J. P.; Borin, A. C. Relaxation Mechanisms of 5-Azacytosine. J. Chem. Theory Comput. 2014, 10, 3915.

(35) Merchán, M.; Serrano-Andrés, L.; Robb, M. A.; Blancafort, L. Triplet-State Formation along the Ultrafast Decay of Excited Singlet Cytosine. J. Am. Chem. Soc. 2005, 127, 1820.

(36) Pedersen, T. B.; Lindh, R.; Aquilante, F. Density fitting with auxiliary basis sets from Cholesky decompositions. Theor. Chem. Acc. 2009, 124, 1.

(37) Challenges and Advances in Computational Chemistry and Physics; Papadopoulos, M. G., Zalesny, R., Mezey, P. G., Leszczynski, J., Eds.; Springer, 2011, Vol. 13.

(38) Zobel, J. P.; Nogueira, J. J.; González, L. Quenching of Charge Transfer in Nitrobenzene Induced by Vibrational Motion. J. Phys. Chem. Lett. 2015, 6, 3006.

(39) Domenicano, A.; Schultz, G.; Hargittai, I.; Colapietro, M.; Portalone, G.; George, P.; Bock, C. W. Molecular Structure of Nitrobenzene in the Planar and Orthogonal Conformations. Struct. Chem. 1990, 1, 107.

(40) Quenneville, J.; Greenfield, M.; Moore, D. S.; McGrane, S. D.; Scharff, R. J. Quantum Chemistry Studies of Electronically Excited Nitrobenzene, TNA, and TNT. J. Phys. Chem. A 2011, 115, 12286.

(41) Li, Q.; Giussani, A.; Segarra-Martí, J.; Nenov, A.; Rivalta, I.; Voityuk, A. A.; Mukamel, S.; Roca-Sanjuán, D.; Garavelli, M.; Blancafort, L. Multiple Decay Mechanisms and 2D-UV Spectroscopic Fingerprints of Singlet Excited Solvated Adenine-Uracil Monophosphate. Chem. - Eur. J. 2016, 22, 7497.

(42) Zugazagoitia, S. J.; Almora-Díaz, C. X.; Peon, J. Ultrafast Intersystem Crossing in 1-Nitronaphthalene. An Experimental and Computational Study. J. Phys. Chem. A 2008, 112, 358.

(43) Reichardt, C.; Vogt, R. A.; Crespo-Hernández, C. E. On the Origin of Ultrafast Nonradiative Transitions in Nitro-Polycyclic Aromatic Hydrocarbons: Excited-State Dynamics in 1-Nitronaphthalene. J. Chem. Phys. 2009, 131, 224518.

(44) Giussani, A.; Worth, A. G. manuscript in preparation.

(45) Chapman, O. L.; Heckert, D. C.; Reasoner, J. W.; Thackaberry, S. P. Photochemical Studies on 9-Nitroanthracene. J. Am. Chem. Soc. 1966, 88, 5550 .

(46) Fukuhara, K.; Kurihara, M.; Miyata, N. Photochemical Generation of Nitric Oxide from 6-Nitrobenzo[a]pyrene. J. Am. Chem. Soc. 2001, 123, 8662.

(47) Plaza-Medina, E. F.; Rodríguez-Córdoba, W.; Morales-Cueto, R.; Peon, J. Primary Photochemistry of Nitrated Aromatic Compounds: Excited-State Dynamics and NO3 Dissociation from 9. Nitroanthracene. J. Phys. Chem. A 2011, 115, 577. 